\title{
Impacts of Immunometabolism on Male Reproduction
}

\author{
Lijun Ye ${ }^{1 \dagger}$, Wensi Huang ${ }^{1 \dagger}$, Su Liu ${ }^{1}$, Songchen $\mathrm{Cai}^{1}$, Ling Hong ${ }^{1}$, Weiqiang Xiao ${ }^{2}$, \\ Kristin Thiele ${ }^{3}$, Yong Zeng ${ }^{1}$, Mingzhe Song ${ }^{2 *}$ and Lianghui Diao ${ }^{1 *}$
}

1 Shenzhen Key Laboratory for Reproductive Immunology of Peri-implantation, Clinical Research Center for Reproductive Medicine, Shenzhen Zhongshan Urology Hospital, Shenzhen, China, ${ }^{2}$ Shenzhen Zhongshan Institute for Reproduction and Genetics, Fertility Center, Shenzhen Zhongshan Urology Hospital, Shenzhen, China, ${ }^{3}$ Division of Experimental Feto-Maternal Medicine, Department of Obstetrics and Fetal Medicine, University Medical Center Hamburg-Eppendorf, Hamburg, Germany

The physiological process of male reproduction relies on the orchestration of neuroendocrine, immune, and energy metabolism. Spermatogenesis is controlled by the hypothalamic-pituitary-testicular (HPT) axis, which modulates the production of gonadal steroid hormones in the testes. The immune cells and cytokines in testes provide a protective microenvironment for the development and maturation of germ cells. The metabolic cellular responses and processes in testes provide energy production and biosynthetic precursors to regulate germ cell development and control testicular immunity and inflammation. The metabolism of immune cells is crucial for both inflammatory and anti-inflammatory responses, which supposes to affect the spermatogenesis in testes. In this review, the role of immunometabolism in male reproduction will be highlighted. Obesity, metabolic dysfunction, such as type 2 diabetes mellitus, are well documented to impact male fertility; thus, their impacts on the immune cells distributed in testes will also be discussed. Finally, the potential significance of the medicine targeting the specific metabolic intermediates or immune metabolism checkpoints to improve male reproduction will also be reassessed.

Keywords: immunometabolism, immune privilege, metabolic reprogramming, immune cells, male reproduction, hypothalamic-pituitary-testicular axis

\section{INTRODUCTION}

Male reproduction is a multi-step process starting from the production of germ cells in testes and transport of sperm to the sperm-egg binding site in the fallopian tube, which is orchestrated by the sophisticated regulation of the endocrine and immune system (1-3). Spermatogenesis is a complex and highly-coordinated cellular differentiation process controlled by the hypothalamic-pituitarytesticular (HPT) axis that modulates gonadal steroid hormones in testes (4, 5). Whereas, spermatogenesis presents a unique challenge to the immune system because meiosis and subsequent cellular differentiation events involved in spermatogenesis occur long after the systemic tolerance is established $(6,7)$. In order to protect the testicular germ cells from detrimental immune responses, the male reproductive system adopts an exclusive immune milieu, which is referred to as the blood-testis barrier (BTB) in testes. The BTB anatomically divides the seminiferous epithelium into the basal compartment containing meiotic (leptotene, 
zygotene, and pachytene spermatocytes) germ cells and the adluminal compartments. All subsequent post-meiotic (round and elongating spermatids) germ cells, thus, allowing early-stage germ cells (spermatogonia) localized outside of BTB to become autoantigenic foreign bodies to the immune system $(8,9)$. Except for the above testicular physical barriers, the testicular immune privilege will be sustained by coordinating systemic immune tolerance, and antigen-specific regulatory immunoregulation (10). Infection or physical trauma of the testis can perturb testicular immune privilege, causing inappropriate immune responses or inflammation, which may result in altered tissue and cellular metabolic function, and eventually leading to impairment of spermatogenesis, autoimmune disorders, and male infertility (11-13).

Metabolism cooperation among testicular cells is crucial for normal spermatogenesis since increased energy requirements during reproduction and metabolic factors play a predominant role in controlling the functional activity of the reproduction endocrine and immunity in testes (14). The establishment of BTB physically and physiological compartmentalize the seminiferous epithelium into two different milieus forming a microenvironment to support spermatogenesis. Metabolic regulation is essential for developing germ cells into mature spermatids due to the specific metabolic demands of germ cells (15). The BTB is composed of specialized junctions between adjacent Sertoli cells, which is located near the basement membrane, is responsible for maintaining the different levels of substances between rete testis fluid and the lymph or plasma (16). Sertoli cells provide structural and functional support for the development of the germ cells due to their role in maintaining the suitable ionic and metabolic microenvironment in testes $(17,18)$. They use different metabolic substrates, including glucose and fatty acids, and growth factors to meet their metabolic demands and nurture germ cells (19-22). Because the testis is a naturally hypoxic organ, Sertoli cells preferentially use glucose and go through anaerobic glycolysis rather than the tricarboxylic acid cycle to meet the specific metabolic demands of germ cell development $(18,23)$. Besides, Sertoli cells regulate testicular immune tolerance by producing anti-inflammatory cytokines and prostanoid molecules, slowing leukocyte migration and inhibiting complement activation and membrane-associated cell lysis (24). In the interstitium, Leydig cells also contribute to the spermatogonial microenvironment by secreting growth factors and steroid hormones whose metabolism is notable in testes $(25,26)$. Androgens in Leydig cells are derived from cholesterol, which metabolizes to progesterone and, subsequently, testosterone (26). Testosterone regulates spermatogenesis and contributes to the maintenance of the BTB (27). In addition to Sertoli cells and Leydig cells, immune cells presenting in the interstitium, such as macrophages, mast cells, $\mathrm{T}$ cells, natural killer (NK) cells, are responsible for the regulation of sperm generation $(28,29)$. Metabolism, as well as the key signaling pathway mediating metabolic activity in various immune cells of human blood or rodent animals, have been elaborated in recently published reviews (30-33). However, even though all testicular cells, including germ cells, Sertoli cells, Leydig cells, testicular macrophages and lymphocytes, can regulate local immunity in the testis, the specific metabolic functions of testicular immune cells and the different metabolic pathways of testicular immune cells in physiological and pathological states have been neglected (29).

Immunometabolism is a recently emerging area of research that focuses on the crosstalk between the immune and metabolic systems, and studies in the field of reproduction have shown that immunometabolic disorders may be associated with infertility (34-36). Accumulating data from cellular and animal researches focusing on how metabolism regulated immune cell function have been reported, which provide new therapeutic opportunities for many diseases related to immune system dysregulation like autoimmune diseases and cancer (37-39). However, little literature on the immunometabolism or metabolism of immune cells in the male reproductive system, neither in animals nor in humans. In addition, metabolic factors play a dominant role in controlling the functional activity of the HPT axis in men due to the increased energy requirements during reproduction. Therefore, men who are overweight and suffer from metabolic syndrome may be at higher risk of infertility than their healthy counterparts (14). In this review, we will focus on the following topics (a) functional impacts of the neuroendocrine-immune systems on male reproduction; (b) the normal metabolic state of immune cells in testes and their alteration in metabolic diseases; (c) potential therapeutic strategies for male infertility based on key immunometabolic targets.

\section{REGULATION OF HPT AXIS AND IMMUNE ON MALE REPRODUCTION}

\section{Regulation of HPT Axis on Male Reproduction}

Both positive and negative feedback regulatory mechanisms homeostatically regulate the HPT axis. The gonadotropinreleasing hormone $(\mathrm{GnRH})$ is the central regulator of the HPT axis and is secreted from the hypothalamus in a periodic pulsatile manner and regulates the synthesis and secretion of gonadotropins, which are luteinizing hormone $(\mathrm{LH})$ and follicle-stimulating hormone (FSH), by the pituitary gland. Gonadotropins, in turn, acts on testes to stimulate the synthesis of sex gonadal steroid hormones and modulates the testicular-specific morphological changes and functions (40). Conversely, testosterone secreted by the testes provides continuous negative feedback to the hypothalamus and pituitary gland to maintain a steady GnRH, LH, and FSH secretion state. Thus, these gonadal steroids, together with pituitary gonadotropins, explicitly establish physiological homeostasis via feedback regulatory mechanisms to keep healthy male reproductive function $(4,41)$.

Inside testes, the Sertoli cells provide morphogenetic support through cell-cell interactions, nutrients, and biochemical components through lactate, hormones, and cytokines to facilitate spermatogenesis (22). Leydig cells are the major site 
for the synthesis of the predominant male steroid hormone (testosterone), and cytokines, such as macrophage-migrationinhibitory factor (MIF), for the regulation and maintenance of spermatogenesis and extra-testicular androgenic and anabolic and anti-inflammatory functions $(42,43)$. All the above components of the HPT axis coordinate to produce sex steroid hormones, maintain spermatogenesis and sperm counts and quality $(27,44)$.

Regulation of metabolic process in testes is another crucial factor that has a direct influence on male reproduction. Germ cells have specific metabolic requirements for their development, preferentially utilizing lactate as a substrate for ATP production (21). Sertoli cells fulfill the energy requirement of the germ cells and themselves through glycolysis and fatty acid oxidation (18). FSH and sex steroid hormones from the HPT axis have been proven as the regulatory factors that modulate Sertoli cell metabolism $(18,45)$. FSH regulates glycolytic metabolism in mature Sertoli cells through increasing glucose uptake and both pyruvate and lactate production. Meanwhile, FSH has a regulatory effect on lipid metabolism by influencing lipid esterification in Sertoli cells $(18,46,47)$. Androgens and estrogens also regulate Sertoli cell metabolism. $5 \alpha-$ Dihydrotestosterone and $17 \beta$-estradiol are reported to regulate glucose uptake and lactate production in Sertoli cells isolated from humans (48). A recent genome-wide study of androgen and estrogen receptor binding sites proved that sex hormones regulate lipid metabolism in adult Sertoli cells from rats by transcriptionally controlling the expression of the genes (49). Despite energy metabolism for germ cell development, Leydig cells are stimulated by $\mathrm{LH}$ and metabolize cholesterol to testosterone and other steroid hormones, which are required for spermatogenesis and other functions for male reproduction (26).

\section{Impact of GnRH and Pituitary Gonadotropins on Immune Function}

The immune system does not work in isolation as neuroendocrine-immune and central nervous systems are integrated through a complex network (50) of signal molecules, including cytokines, hormones, and neurotransmitters $(51,52)$. Evidence suggests the hypothalamic-pituitary-gonadal (HPG) axis and related hormonal system may modulate immune function (53). Physiologically, GnRH acts as an autocrine or paracrine factor to regulate both neuroendocrine and immune functions. Immunoreactive and bioactive $\mathrm{GnRH}$ receptor (GnRH-R) has been identified in human peripheral lymphocytes, implicating that $\mathrm{GnRH}$ may function as an autocrine or paracrine factor to regulate immune functions (54-56). Blockade of central and peripheral GnRH-R during maturation of both the HPG axis and brain-thymus-lymphoid axis remarkably impairs the development of the immune system (57). The administration of $\mathrm{GnRH}$ antagonist into rodent and primate fetuses resulted in the suppression in the numbers of thymocytes and immune cell development, suggesting $\mathrm{GnRH}$ plays a crucial role in immune system modulation and development $(56,58)$. In mammals, $\mathrm{GnRH}$ induces the expression of cytokines such as interleukin-2
(IL-2) and interferon- $\gamma$ (IFN- $\gamma$ ), promoting their proliferation and activation of immune cells (59). Taken together, these pieces of evidence indicate that GnRH may be directly involved in the cellmediated and humoral immune response.

Nevertheless, a paucity of studies illustrating the immunomodulatory actions of FSH and $\mathrm{LH}$ experimental and clinical evidence suggested that these two gonadotropins induce the proliferation of immune cells and modify cytokine (e.g., IL10 , interferon- $\gamma$ ) production $(60,61)$. After treatment with gonadotropin, the immune cell populations were altered in male patients with idiopathic hypogonadotropic hypogonadism $(\mathrm{IHH})$, suggesting that gonadotropin could modulate both cellmediated and humoral immunity (62).

Collectively, Sertoli cell metabolism plays a decisive role in the male reproductive physiology process. And FSH and sex steroid hormones (androgens and estrogens) from the HPT axis have been shown to regulate Sertoli cell metabolism.

\section{Impact of Sex Steroid Hormones on Immune Function}

Besides sexual differentiation and reproduction, sex steroid hormones also influence immune function due to the presence of hormone receptors on immune cells $(63,64)$. Owing to lipophilic properties, sex steroid hormones can alter membrane properties of immune cells by integrating into their membrane, leading to changes in the immune cell functions (51). Androgens and estrogens represent the two major gonadal steroid hormones produced by the testes. Estrogens and androgens exert their effects through binding to their well-recognized estrogen receptors (ERs) and androgen receptors (ARs), respectively, which are expressed in primary lymphoid organs as well as various immune cells (59). Thus, sex steroids, particularly androgen and estrogens, can modulate immune cell development and immune response and also regulate reproductive functions in males.

\section{Androgen}

Men produce 20 times more testosterone than women, and the incidences of autoimmune disease remain relatively lower among men (65-67). Thus, androgens are believed to affect both the development and function of the innate immune response and the adaptive immune system $(51,68)$. In human males, androgen deficiency is characterized by an increase in serum levels of inflammatory cytokines, such as IL-1 $\beta$, tumor necrosis factor $\alpha$ (TNF- $\alpha$ ), and the number of macrophages in the circulation (69). Furthermore, loss of testicular immune privilege was detected in the mice with deficiency of the androgen receptor in Sertoli cells, revealing the role of androgen in testicular immune privilege (70). Testosterone, as the dominant androgen in testes, its level is decreased in experimental autoimmune orchitis (EAO, a model of male immune infertility) rat. Protective effect is shown in the development of disease and the inflammatory response in EAO rat treated with testosterone supplementation, which prevented the increase of macrophage and reduced the number of $\mathrm{CD}^{+} \mathrm{T}$ cells accompanied with increasing number of regulatory $\mathrm{T}$ cells 
(Tregs) in testes comparing with the EOA rat without testosterone replacement (71). The mechanism of testosterone actives Tregs is that testosterone induces expression of Foxp3 in human $\mathrm{T}$ cells through binding of the AR to gene regulatory sequences, which leads to the generation of $\mathrm{CD} 4^{+} \mathrm{CD} 25^{+} \mathrm{Foxp} 3^{+}$ regulatory $\mathrm{T}$ cells, which are viewed as important players in testicular immune tolerance (72). Furthermore, testosterone inhibits the lipopolysaccharide-induced inflammatory response on TNF- $\alpha$ mRNA expression both in Sertoli cells and peritubular cells which support spermatogenesis and transport of spermatozoa as well as testicular immune regulation, while no effect was found in testicular macrophages (73). Taken together, these studies suggested that androgens modulate not only the numbers but also the function and responses of innate immune cells in mammals, as well as the immunosuppressive effect in male reproduction through influencing the numbers and secretion of testicular immune cells. However, the role and mechanism of androgens in regulating the testicular immune status remains to be clarified and elucidated.

\section{Estrogen}

Estrogens, as relevant physiological regulators in men, exhibit an immunoenhancing effect (66). Two intracellular ER subtypes $(\mathrm{ER} \alpha$ and $\mathrm{ER} \beta)$ are expressed in the mammalian immune system to regulate the innate and adaptive immune system as well as immune cell development $(64,68,74)$. Of note, both ER $\alpha$ and ER $\beta$ are expressed by a diverse array of immune cell types, including T cells, B cells, macrophages, dendritic cells (DCs), and NK cells $(75,76)$. Estrogen regulates immunity and maintains immunometabolic function in males $(77,78)$. In transgenic male mice that overexpress human aromatase genes (AROM+ mice), increased estradiol promoted testicular macrophage activation; however, testicular macrophages were enhanced in a rat model of EAO, indicating the stimulating effect of estrogens on immunoregulation of male reproductive function $(79,80)$.

Collectively, sex steroids function as regulators of the immune system, and androgens and estrogens affect different subsets of immune cells. In general, androgens appear to predominantly have immunosuppressive activity, while estrogen exhibit an immunoenhancing effect on immune cells and immune activity (Figure 1). Thus, androgens exert suppressive effects in the immune-privileged environment of testes, while estrogens exert immunoenhancing activities in testes, which warrants further investigation.

\section{POSSIBLE CONTRIBUTION OF METABOLISM OF IMMUNE CELLS TO MALE REPRODUCTION}

The testicular interstitial space possesses potent immunoregulatory activities through the production of cytokines and other immunoregulatory molecules such as androgens by interacting cell types, including macrophages, DCs, T cells, NK cells, mast cells, and Leydig cells $(6,9)$. For instance, the anti-inflammatory factor TGF- $\beta$ and IL-10, can suppress the immune response to maintain the immune homeostasis of testes $(6,9)$. These immune cells primarily express a high tolerance to germ cell autoantigens,

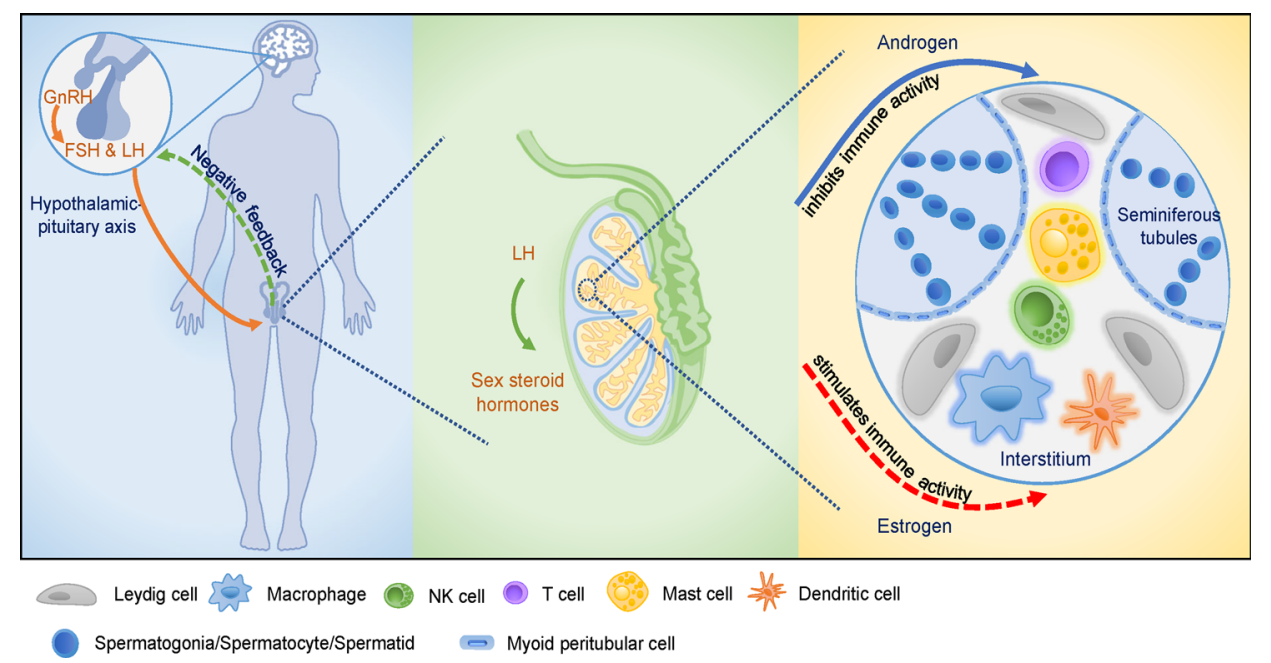

FIGURE 1 | The hypothalamic-pituitary-testicular (HPT) axis and the testicular immune-privileged microenvironment. GnRH stimulates the release of pituitary gonadotropins, induces male reproductive function as well as affects cellular and humoral immune function. GnRH promotes the proliferation of immune cells and modifies cytokines production. Pituitary gonadotropins are involved in cellular and humoral immune development. Sex steroid hormones are secreted by the stimulation of LH that acts on Leydig cells in testis. Androgens and estrogens affect male reproductive function via modulation of the immune system and immune response. Various cell types present in the testicular interstitial space, including macrophages, DCs, T cells, NK cells, mast cells, and Leydig cells, providing a unique microenvironment for testicular functions. Androgens play crucial roles in maintaining the integrity of testicular immune-privileged microenvironment (solid arrow), while estrogens seem to play a stimulatory role in testicular immunoregulation which needs further investigations (dotted arrow). 
meanwhile maintain protection against microbial infections. At present, the microenvironmental signals like androgens, prostaglandins, and corticosterone have been indicated to influence the phenotype and function of testicular immune cells (81). Since metabolic flux can dictate cell fate like immune cell effector and regulatory function, the field of immunometabolism has seen tremendous development over the past decade (33). Yet metabolic reprogramming in immune cells of testes has not been illustrated. This may be due to a paucity of nonpathological tissue samples in human (82). Conceivably, immunometabolism pattern has been partly established in tumor and gravid uterus which are also immune-privileged sites, which could be used as reference for the new areas of research in immunometabolism in male reproduction. In this article, therefore, we attempt to establish the possible immunometabolic pathways involved testicular function.

\section{Macrophages}

In testes, macrophages represented the most abundant immune cells in the interstitial space (83). For example, rat testicular macrophages were accounting for approximately $80 \%$ of the testicular leukocytes (84). A recently study in human testes revealed that testicular resident macrophages are approximately $62 \%$ of testicular myeloid cells and express 6-fold higher levels of the M2 macrophages marker (CD163) than blood monocytes (85). According to the morphology and localization, human testicular macrophages could be classified into interstitial and peritubular macrophages; but no marker has been found to distinguish both types (86). Unlike in humans, mouse testicular interstitial and peritubular macrophages were characterized by $\mathrm{CD}_{64}{ }^{\mathrm{hi}} \mathrm{MHCII}^{\mathrm{lo}}$ and $\mathrm{CD} 64^{\mathrm{lo}} \mathrm{MHCII}{ }^{\mathrm{hi}}$, respectively $(87,88)$. Once established in the niche, except the empty niche, these macrophages self-maintain for long periods of time without replenishment from blood monocytes in the steady condition (88). Interstitial macrophages closely contact with Leydig cells, which might contribute to facilitate testosterone. For example, when Leydig cells cultured in testicular macrophages-conditioned medium, the production of testosterone significantly increased, whereas had less effect on conditioned medium from peritoneal macrophages (89). Subsequently, macrophage-derived factor 25hydroxycholesterol, might works as an exogenous substrate engaging in testosterone production, had been found to increase (90). Moreover, in both the colony stimulating factor 1 (CSF1) mutation mouse lacked most macrophage populations and the transient macrophage depletion mouse model, intratesticular testosterone were reduced $(91,92)$. Testosterone regulated downstream gene expression like Rhox5 through interacting with androgen receptor in Sertoli cells, and then regulated spermatogenesis processes, including maintenance of spermatogonial numbers and $\mathrm{BTB}$, completion of meiosis by spermatocytes, adherence of elongated spermatids to Sertoli cells, and the release of mature spermatozoa $(93,94)$. On the other hand, dihydrotestosterone, a derivative of testosterone, modulates levels of glycolysis-related transporters (glucose and monocarboxylate transporter) and enzymes (phosphofructokinaseland lactate dehydrogenase), and consequently acts on glucose metabolism in rat Sertoli cells $(95,96)$. Glucose metabolism within Sertoli cells is crucial for spermatogenesis since developing germ cells consume lactate produced by Sertoli cells as their main energy source (97). Testicular macrophages might express CSF1 and retinoic acid biosynthesis enzymes ALDH1A2 and RDH10 to promote spermatogonial proliferation and differentiation. In macrophages-depleted testes, followed by ALDH1A2 and RDH10 decrease, spermatogonia differentiation would be disrupted (98). However, it can't identify whether these evidences resulted from peritubular macrophages depletion or interstitial macrophages depletion leading to reduce these factors production by Leydig cells, since the depletion models targeted all macrophages. Winnall and Hedger summarized four subsets of rat testicular macrophages, including $\mathrm{CD}^{+} 8^{+} \mathrm{CD} 163^{-}$(21.7\%) newlyarrived macrophages and $\mathrm{CD} 68^{+} \mathrm{CD} 163^{-}$infiltrating macrophages accounting for $21.7 \%, \mathrm{CD}^{+} 8^{+} \mathrm{CD} 163^{+}$intermediate macrophages (36.7\%), and $\mathrm{CD}^{-} 8^{-} \mathrm{CD} 163^{+}$resident macrophages (42\%) (83). Recently, this idea has been renewed by the data, utilizing flow cytometric analyses, that all, not only $57 \%$, testicular macrophages are positive for $\mathrm{CD} 68$ and comprised by $\mathrm{CD}^{+} 8^{+} \mathrm{CD} 163^{+}(80 \%)$ and $\mathrm{CD}^{+}{ }^{+} \mathrm{CD} 163^{-}$cells $(20 \%)(81)$.

In fact, rat testicular macrophages characterized by high level of CD163 that were related to maintain testicular immune privilege through secreting large amounts of the antiinflammatory cytokine like IL-10, and inducing expansion of immunosuppressive Tregs $(81,85,99)$. Similarly, macrophages in mouse testes also display an immunosuppressive phenotype by expressing significantly higher levels of immunosuppressive genes, namely Mrc1, Dab2, Igf1, and Lgals3 (88). In accordance with these evidences, previous data suggested that the number of CD $25^{+}$Foxp $^{+}$Tregs would increase after coculture of testicular macrophages and splenic $\mathrm{T}$ cells (81). In general, classically activated macrophage phenotype or M1 macrophages activated by the stimulation of TLRs through bacterial lipopolysaccharides (LPS) or the cytokine IFN- $\gamma$ are pro-inflammatory, like peritoneal macrophage. However, rat testicular macrophages are specifically polarized to regulatory phenotype with similar properties as M2 phenotype under LPS/IFN- $\gamma$ stimulation (99, $100)$. Even during inflammation resulting from uropathogenic Escherichia coli (UPEC), mouse resident macrophages (F4/ $80^{\text {hi }} \mathrm{CD} 11 \mathrm{~b}^{\text {lo }}$ ) were only number proliferation, but not transformed to inflammatory macrophages $\left(\mathrm{F} 4 / 80^{\mathrm{lo}} \mathrm{CD} 11 \mathrm{~b}^{\mathrm{hi}}\right.$ ) that impaired testis tissues and spermatogenesis (88). It can be confirmed by the evidence that focal impairment of spermatogenesis induced by UPEC infection in wild type mice was ameliorated in chemokine receptor 2-deficient mice, which lack peripheral blood monocytes due to defective egress of Ly6 $C^{\text {hi }}$ monocytes from the bone marrow (88). This is partly because testicular macrophages exhibit an attenuated response to inflammatory cues by inhibiting TLR cascade gene expression and blocking the nuclear factor $-\kappa \mathrm{B}(\mathrm{NF}-\kappa \mathrm{B}$, a proinflammatory transcription factor) signaling pathway (101). As a consequence, the process leads to the low production of pro facilitating the protection of the delicate germ cells from a 'cytokine storm' (82). Meanwhile, testicular macrophages also produce much lower concentration proinflammatory cytokines than peritoneal macrophages to retain bactericidal activities through the 
activation protein transcription factor 1 (AP-1) and cAMP response element binding protein (CREB) signaling pathways (100). Secondly, high amounts of testosterone (around100-fold higher than in serum), prostaglandins (PGs, like $\mathrm{PGE}_{2}$ and $\mathrm{PGI}_{2}$, around 3000-fold higher than in serum), and corticosterone (around 7-fold higher than in serum) in testicular interstitial fluid are associated with the establishment and maintenance of the immunosuppressive phenotype of M2 macrophage (81). In support, these molecules polarized GM-CSF-induced monocytederived M1 macrophages to the M2 macrophage phenotype characterized by significantly expression of IL-10 and CD163 (81). Among these molecules, testosterone and $\mathrm{PGE}_{2}$ suppressed the activation of the NF- $\kappa \mathrm{B}$ signaling pathway by deferring $\mathrm{I} \kappa \mathrm{B} \alpha$ degradation, and $\mathrm{PGE}_{2}$ concomitantly activated the CREB and signal transducer and activator of transcription 3 (STAT3) antiinflammatory signaling pathways in LPS stimulated macrophages. However, corticosterone did not attenuate the activation of the NF$\kappa \mathrm{B}$ signaling pathway and increase the activation of STAT3, but activated the CREB signaling. Endogenous corticosterone produced by testicular macrophages was the principal molecule in maintaining testicular macrophages phenotype and function. This idea could be supported when peritoneal macrophages cultured in testicular macrophages supernatant, the secretion of TNF- $\alpha$ was significantly reduced upon stimulation with LPS, an effect abolished using a corticosterone inhibitor (81). Furthermore, the metabolic reprogramming of immune cells is required for the polarization and activation of macrophages, which is increasingly apparent in macrophage populations derived from the mouse peritoneum (102) and bone-marrow (103, 104). Immunosuppressive M2 macrophages induced by IL-4/IL-13 maintain high levels of oxygen consumption rate to reduce glucose flow through the pentose phosphate pathway (PPP) to oxidative phosphorylation (OXPHOS) and tricarboxylic acid (TCA) cycle (102-104). M2 macrophages also exhibited a significant increase of uptake and oxidation of fatty acids (FAs) which are suppressed in M1 macrophages (105). Testicular somatic cells, such as Sertoli cells, Leydig cells and macrophages, synthesize high levels of FAs metabolites to sustain the M2 phenotype. Coinciding with this, rat testicular prostaglandins that were mainly produced by these cells from arachidonic acid by the action cyclooxygenase (COX) are much higher than in serum under physiological condition $(81,106)$. However, COX/ prostaglandins system was related with infertile patients with impaired spermatogenesis (106). This discrepancy may imply that PGs play distinctly different roles in testes of different species. Thus, the potential mechanism of COX/prostaglandins system on male infertility need to be further investigated. Different from inflammatory macrophages, M2 macrophages metabolize arginine to polyamines that are highly immunosuppressive acting by high levels of arginase 1 (ARG1) (107). Elevated lactate produced by tumor cells has been shown to promote the M2-like polarization and increase ARG1 expression (108). Concomitantly with efficient glycolysis process, Sertoli cells produced abundant lactate and secreted them into seminiferous epithelium for germ cells (97). But whether Sertoli cells-produced lactate polarized testicular macrophages toward the M2 phenotype is less clear.
Conversely, inflammatory M1 macrophages, induced by IFN- $\gamma /$ LPS, exhibited glucose metabolism shift towards the anaerobic glycolytic pathway and the PPP to meet the rapid energy requirements, and increased demands for biosynthetic precursors used for the synthesis of pro-inflammatory factors (e.g., NO, TNF- $\alpha$, IL-6) (109). Consequently, this metabolic reprogramming leads to increased lactate, succinate, NADPH necessary for reactive oxygen species (ROS) production (107). Arginine is also a critical nutrient for M1 macrophages to generate cytotoxic nitric oxide (an important pro-inflammatory mediator) by inducible nitric oxide synthase (iNOS) (107). However, in nutrient deficits tumor tissue, an immunologically privileged site, when glycolysis, PPP and TCA cycle were suppressed, the generation of succinate, NADPH and ROS were concomitantly limited, M1 macrophages function were severely limited (107). In this context, testicular interstitial space maintained immunosuppressive state whether partially due to the nutrient constitution, where remains to be investigated.

Overall, the above evidences indicate that testicular macrophages might enhance oxidative metabolism and decrease anaerobic metabolism to maintainM2 macrophages phenotype. In fact, further studies are needed for the metabolism pattern of macrophages in testes, which may help to understand the role of macrophages in spermatogenesis.

\section{Dendritic Cells}

Testicular DCs, a small immune cell population within testes, are phenotypically immature and functionally tolerogenic DCs under physiological conditions. They are involved in effector T cell inactivation and Tregs development and are associated with the adaptive immune system of testes under physiological conditions (110). Moreover, immature DCs might be involved in recognition of normal sperm antigens and induction of immune tolerance to protect sperm cells under physiological conditions (110). Fatty acid oxidation (FAO) and OXPHOS are essential catabolic process for the development of immature DCs $(111,112)$. Notably, drugs (e.g., vitamin-D3) that promote the OXPHOS pathway may facilitate tolerogenic DC (adopted tolerant status) phenotype and function such as the production of IL-10 (113). Moreover, inhibition of FAO prohibited the function of immature DCs and partially restored $\mathrm{T}$ cell stimulatory capacity (111). Indoleamine 2,3-dioxygenase (IDO), an enzyme for catalyzing the metabolism of tryptophan and then generating kynurenine, usually maintains a basal level in DCs (114). Functioning as an endogenous ligand for aryl hydrocarbon receptors on $\mathrm{T}$ cells, kynurenine has been found to induce the generation of Foxp $3^{+}$Tregs and the upregulation of programmed cell death receptor 1 (PD-1) on activated $\mathrm{CD} 8^{+} \mathrm{T}$ cells, both of which were associated with immunosuppression $(115,116)$. IDO is reported to induce DCs to initiate immune tolerance and to stimulate the development of Tregs in tumors and pregnant uterus both are immunologically privileged site like testes (117-119). Recently, the IDO-based mechanism has also been identified to be involved in testicular immune privilege (120). The expression of IDO is rapidly increased when DCs 
suffer from LPS/IFN- $\gamma$-stimulation, leading to limited microbial growth and reduced injurious hyperinflammatory responses (121, 122). However, testicular DCs mildly expressed IDO, meanwhile IDO activity is reduced in EAO rat $(120,123)$. These differences might be attributed to the fact that the Sertoli cells indirectly inhibit LPS-induced DCs maturation through paracrine effect. Supporting this idea, when bone marrow-derived DCs cocultured with Sertoli cells from mouse testes that secreted galectin-1, the expression of iNOS, COX2, and IDO are decreased, whereas the levels of IL-10 and TGF- $\beta 1$ are significantly increased in LPS-stimulated DCs (124).

However, DCs maturation under the pathological conditions overcome the immune tolerance by the local activation of autoreactive $\mathrm{T}$ cells by upregulating co-stimulatory proteins such as CD40, CD80, CD86, inflammatory cytokines, major histocompatibility complex (MHC) class-II, which trigger autoimmunity and causes male infertility (6). This has been demonstrated in azoospermic testes of human with chronic inflammation and atrophy testes of rats with EAO $(12,125)$. The predominant metabolic mode of mature DCs following LPS/ IFN- $\gamma$-stimulation induces a switch from OXPHOS to glycolysis, with a decrease in TCA cycle activity, and an increase in lactate production and flux through the PPP (126-128). Besides, mature DCs induced by LPS also increase the expression of iNOS, which generates $\mathrm{NO}$, a reactive nitrogen species that can inhibit mitochondrial respiration, thereby dampening OXPHOS (129). However, it has not been reported how metabolic reprogramming regulates the development of mature DCs in testes.

\section{Lymphocytes}

In normal human and rat testes, lymphocytes were according for $10 \%-20 \%$ of the total leukocyte population and sparsely distributed throughout the interstitial space, whereas B lymphocytes were not found $(84,86)$. During inflammation induced by infection or autoimmunity, however, the number of lymphocytes, such as effector T helper cells (Th1 and Th17), as well as Tregs, increases significantly within the testicular interstitial space $(28,130)$. Comparing with peripheral blood where $\mathrm{CD} 4^{+} \mathrm{T}$ cells were the major lymphocyte subset, $\mathrm{T}$ cells in rat testes are predominantly of the $\mathrm{CD}^{+}$subset, and a large population of NK cells were also visible (131). This might be consistent with consolidated immunosurveillance and a reduced capacity for initiating antigen-specific immune responses. There was reverse correlation between the largely number of NK cells and the metastatic incidence of gastric, renal, and prostate carcinomas (132).

Foxp $3^{+}$Tregs, the powerful immunosuppressive cells, are found in rat, mouse and human testes under physiological conditions, which may be associated with the immunosuppressive characteristics of testes $(125,133,134)$. The data about Tregs in human blood reveal that testosterone supplement induces a strong increase in the $\mathrm{CD} 4{ }^{+} \mathrm{CD} 25^{+} \mathrm{Foxp}^{+}$ Tregs population via Foxp3 through androgen-mediated binding of AR to the Foxp3 locus (72). However, whether or how testosterone modulates the activation and function of $\mathrm{T}$ lymphocytes remains less clear. On the other hand, testosterone might inhibit the activation of $\mathrm{CD}^{+}$and $\mathrm{CD} 4^{+} \mathrm{T}$-cell subset. When Leydig cells were destroyed by ethane dimethane sulfonate, the number of $\mathrm{CD}^{+}$and $\mathrm{CD}^{+} \mathrm{T}$ cells rapidly increased. The addition of testosterone cooperating with recovery Leydig cells would reduce the number of $\mathrm{CD}^{+}$and $\mathrm{CD} 4^{+} \mathrm{T}$ cells to lower than the control levels (135). Similar to Leydig cells, Sertoli cells have been reported to induce the differentiation of Foxp $3^{+}$Tregs via Notch pathway signaling through secreting JAGGED1 (136). In fact, Tregs generation and suppressive functions are also highly dependent on mitochondrial FAO and OXPHOS to oxidize exogenous FAs, which is stalled by enhanced glycolysis. Numerous regulators of Tregs suppressive function, including adenosine monophosphate-activated protein kinase (AMPK), and transcription factor Foxp3, by inhibiting glycolysis and promoting FAs oxidation through suppression of mTOR activity (137). Foxp3 reduces glucose uptake in Tregs by inhibiting the expression of glucose transporter 1 (GLUT1). Besides, AMPK, another regulator of Tregs suppressive function, inhibits glycolysis, and promotes FAO through the suppression of mTOR activity (137). Interestingly, in response to TLR signals, Tregs upregulate GLUT1 expression and anaerobic glycolysis to promote proliferation and inhibit their suppressive function. In inflammatory testes, although $\mathrm{CD}^{+}$and $\mathrm{CD}^{+}$Tregs are increased, and TGF- $\beta$ is expressed, more effector T cell subsets can overwhelm the inhibitory effect of Tregs by producing proinflammatory cytokines like TNF- $\alpha$ and IL-6 (138). Thus, Tregs alone may not be sufficient to limit excessive $\mathrm{T}$ cells activation in autoimmune settings.

$\mathrm{T}$ cells activation leads to dynamic transformation in cell metabolism to protect against pathogens and to coordinate the function of other immune cells. T cells accomplish bioenergetic demands for activation by undergoing anaerobic glycolysis, a process frequently observed in highly proliferative cells in which glucose is fermented into lactate rather than oxidized in mitochondria. Recent studies have reported the dynamic profile of $\mathrm{CD}^{+}$and $\mathrm{CD} 8^{+} \mathrm{T}$ cells after activation and revealed that glucose acts as a crucial contributor to fuel effector responses and proliferation of immune cells $(139,140)$. $\mathrm{PGE}_{2}$ secreted by Leydig cells may transform $\mathrm{T}$ cells from proinflammatory phenotype (Th1) to anti-inflammatory phenotype (Th2) (141). NK cells, comparable to lymphoid lineage members, also upregulate anaerobic glycolysis and OXPHOS during their activation and effector function, which parallels with the immunometabolism of effector T cells (137). Inconsistent with glucose transport, hypoxia-inducible factor $1 \alpha$ (HIF- $1 \alpha)$, and mTOR highlight metabolic control points in both T cells and NK cells. Despite these similar nodes of immunometabolism, NK cells exhibit a differential reliance on OXPHOS for IFN- $\gamma$ production, while $\mathrm{T}$ cells rely profoundly on glycolysis to produce IFN- $\gamma(142,143)$. Furthermore, numerous inhibitory molecules, such as IDO and PD-1, alter T cells metabolism by reducing T cells GLUT1 expression and then inhibiting glucose uptake $(144,145)$. The inhibition of both IDO and PD-1 is also observed in NK cell; however, whether they impair NK cells effector function by altering metabolism remains elusive (146). Given that Sertoli cells express IDO and programmed death-1 
ligand-1 (PD-L1) and also inhibit the activation of T cells, and NK cells, it is warranted to elucidate whether Sertoli cells regulate these effector cells by paracrine action to control their metabolism. It is also implicated that Sertoli cells may partly contribute to immunosuppression for the testicular immune privilege in the similar way.

\section{Mast Cells}

Mast cells are scarce in rat and mouse, but are more frequent in human, all of which are quiescent under physiological status. Mast cells in testicular interstitial space have long been recognized to regulate steroidogenesis by Leydig cells. A growing body of evidence indicate that increasing number of mast cells is associated with idiopathic male infertilities and spermatogenic disorders (147). Moreover, mast cells are intermingled with testicular peritubular cells in the tubular wall of infertile men and may provide a possible source of highly increased amounts of extracellular ATP. Besides, upon the activation of immune cells, the extracellular ATP may function as a hazardous molecule to peritubular cells by activating their purinoceptors (P2RX4 and P2RX7). Subsequently, ATP-mediated events in peritubular cells lead to enhanced expression of pro-inflammatory molecules like IL-6 and CCL7 (147). Evidence shows that inhibiting glycolytic ATP production may suppress IL-33-induced bone marrow-derived mast cell activation and proinflammatory factor IL-6 and tumor necrosis factor (TNF) production (148). Thus, mast cells may be involved in testicular inflammation via their metabolic products.

In conclusion, both the microenvironment and metabolism reprogramming of immune cells participate in the establishment of their phenotype and immunoregulatory function. Mainly, glucose and FA metabolism promote the cell differentiation towards immunologically tolerant cell phenotypes; in contrast, inflammatory phenotype cells use glycolysis as a leading source of energy more than mitochondrial OXPHOS for rapid removal of pathogens (Figure 2). The disruption of metabolic reprogramming may result in inflammation, autoimmunediabetes, metabolic syndrome, and even male infertility. Therefore, exploration of the functions of immune cell metabolism in testes is imperative in further understanding the molecular and cellular processes underlying male infertility. And, this may facilitate the development of novel anti-inflammatory therapeutics targeting immunometabolism.

\section{IMMUNE DYSFUNCTION AND METABOLIC DISORDER IN THE MALE REPRODUCTION}

\section{Impact of Metabolic Disorders in Immune Cells and Functions on the Male Reproduction}

Although various immune cells have been identified in testes, metabolism of these immune cells remain to be elucidated. Molecular and cellular alterations in the metabolic state under the physiological or pathological conditions in testes remain mostly unexplored. Metabolic reprogramming of immune cells plays a predominant role in regulating their phenotype as well as their plasticity. Considering the abundant immune cells in testes, activation and polarization of macrophages by pro-inflammatory stimuli elicits metabolic reprogramming, further leading to a shift in the balanced mitochondrial metabolism towards ROS generation (149). ROS can stabilize HIF-1 $\alpha$, thus promoting glycolysis and supporting the transcription of the proinflammatory cytokine IL-1 $\beta(32,129)$. IL-1 system may involve in the autocrine regulation of Sertoli cell function in vitro, and IL-1 $\beta$ is reported to reduce testicular steroidogenesis of the immature rat that is 21-day-old $(150,151)$. Besides, it is universally acknowledged that supraphysiological ROS levels lead to defective sperm function by lipid peroxidation of cytomembrane and DNA damage as well as protein oxidation that leads to inactivation of enzymes, which ultimately results in male infertility $(152,153)$. Types of cytokines secreted from various metabolic processes of different immune cells due to stimulations are not only limited to macrophages, but these cytokines may also conversely influence the functions and metabolism of immune cells (154). Hence, upon activation, immune cells may cause alteration in the cellular metabolism, leading to the secretion of cytokines that may affect testes' normal immune cell functions.

\section{Cytokines Changes in Inflammation in the Male Reproduction}

Inflammation of the male reproductive system is inevitably related to changes in the levels of cytokines. Cytokines are released from different immune cells present in the male reproductive system and also in response to foreign antigens and pathogens and chronic inflammation (155). The secretion of cytokines represents the first indication from the innate host defense to combat inflammation of the reproductive tract. Orchitis is one of the common etiological factors related to human subfertility/infertility. Studies on autoimmune orchitis indicated that the initial phase of inflammation comprised of the recruitment of the immune cells, followed by their activation and increased production of pro-inflammatory cytokines such as IL-1 and TNF- $\alpha(12,156)$. Theses complex array of proinflammatory cytokines affects BTB permeability, which enters the seminiferous epithelium, leading to the induction of apoptosis of germ cells (12). Increasing evidence indicates that elevated levels of cytokines exist in the semen, including IL-1 $\beta$, IL-6, and IL-8, which are frequently associated with inflammation and infection of the male reproductive system (157-159).

Moreover, inflammation in the male reproductive system has been identified to increase ROS levels, resulting in cell damage concomitantly, apoptosis or necrosis $(28,160)$. ROS is not only to be involved in the damage of spermatogenic cells and sperm but also impairs Sertoli cells and Leydig cells in testes, which contributes to spermatogenesis dysfunction (161-163). Released pro-inflammatory cytokines in semen during inflammation might modulate the balance of prooxidative and antioxidative systems to the advantage of the oxidative stress, resulting in 


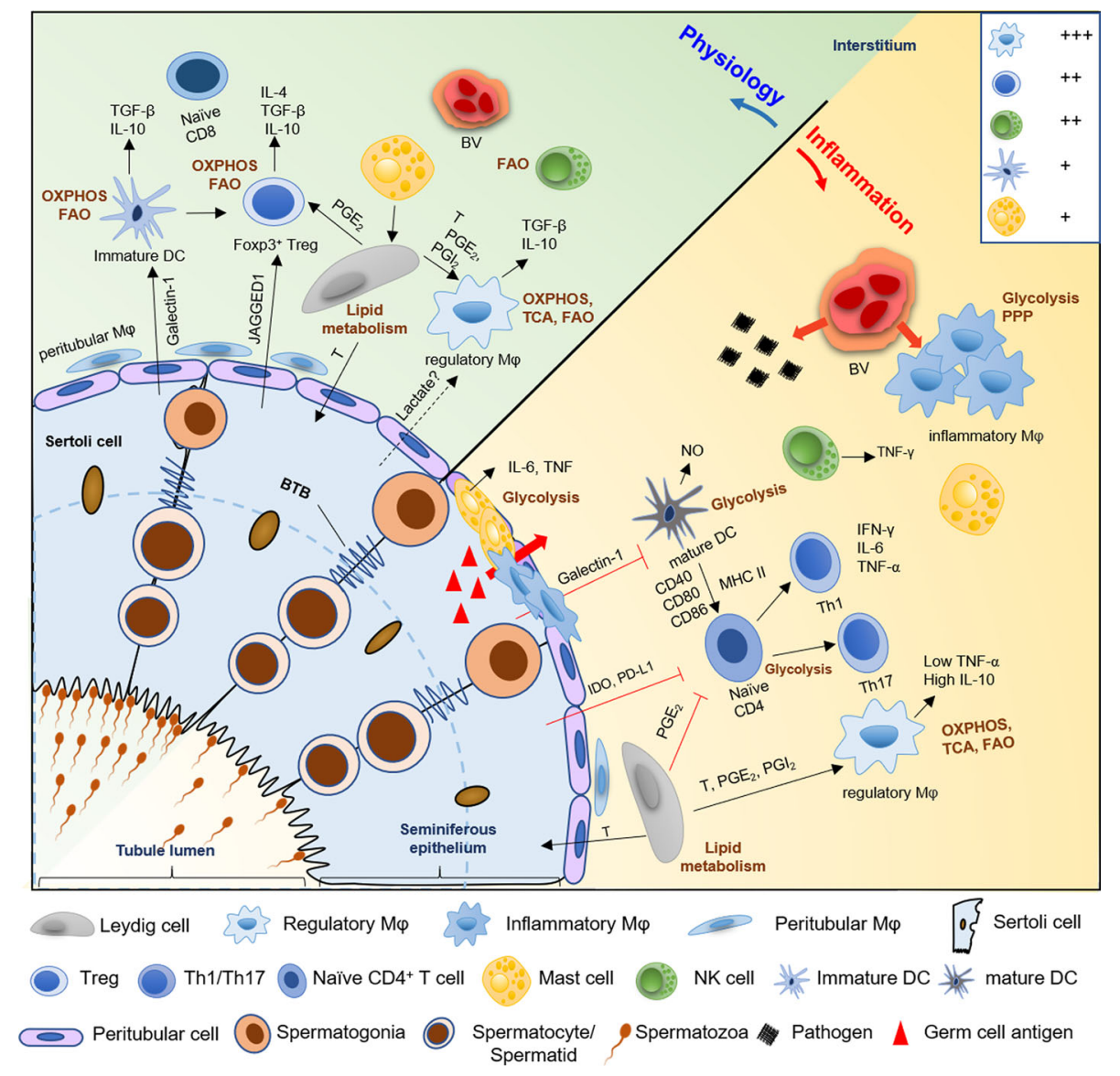

FIGURE 2 | A schematic diagram of the hypothetical metabolic homeostasis of immune cells in testes under physiological or inflammatory condition. In normal testes, immunologically tolerant cell phenotypes, comprising with macrophages (M $\varphi$ ), immature DCs, Tregs, and regulatory NK cells, principally rely on OXPHOS and fatty acid oxidation pathway to fuel immunosuppressive functions and synthesis of anti-inflammatory cytokines (e.g., IL-10 and TGF- $\beta$ ). However, when testes suffer from pathogens or germ cell antigens attack, the number of macrophages and mast cells are markedly increased, and the location of these cells partially shift from the interstitium to the tubular compartment of infertile men testes. Furthermore, inflammatory phenotype cells such as infiltrating macrophages, mature DCs, effector T helper cells, and mast cells markedly show a metabolic shift towards the anaerobic glycolytic pathway to meet the rapid energy requirements and increased demands for synthesis of proinflammatory cytokine, like IL-6, NO and TNF- $\alpha$. Then this cause 'cytokine storm' to disrupt the delicate equilibrium between immune privilege and tolerance, which trigger testes inflammation and impair normal spermatogenesis, followed by male infertility. Meanwhile, Sertoli cells also contribute to the immune-privileged status of mammalian testes, especially, maintain immature DCs, and inhibit effector T cells and NK cells via paracrine cytokines IDO and PDL1. Similarly, Leydig cells play an immunoregulatory effect on maintenance of regulatory macrophage phenotype and inhibition of $T$ cells immune responses through secreting lipid metabolites, such as testosterone, $\mathrm{PGE}_{2}$ and $\mathrm{PGI}_{2}$. Treg, regulatory T cells; DC, dendritic cell; Th, T helper cell; FAO, fatty acids oxidation; OXPHOS, oxidative phosphorylation; TCA, tricarboxylic acid; PPP, pentose phosphate pathway; T, testosterone; PGE2 and PGI2, prostaglandins E2 and I2; IDO, indoleamine 2,3-dioxygenase; PDL-1, programmed death ligand-1; NO, nitric oxide; BV; blood vessel. +++, most abundant; ++, relatively abundant; +, present (28).

permanent peroxidative damage to spermatozoa, consequent effects in the passage of defective paternal DNA on to the conceptus and fertilizing potential $(152,153,164,165)$.

\section{Systematic Metabolic and Immune Disorders in the Male Reproduction}

Metabolic disorders related to systematic diseases may also disrupt the balance of cellar metabolic processes, immune environment, and redox activities. Obesity and metabolic syndrome are characterized by hyperinsulinemia, hyperlipidemia, hyperleptinemia, and chronic inflammations, which may also directly impair testicular functions by dysregulating the HPT axis and immune functions in male reproduction $(166,167)$. Men with a BMI range from $35 \mathrm{~kg}$ $\mathrm{m}^{-2}$ to $40 \mathrm{~kg} \mathrm{~m}^{-2}$ have more than $50 \%$ reduction in total and free testosterone levels than lean men (168). The decreased level of testosterone is associated with diminished $\mathrm{LH}$ and deteriorated semen quality (including reduced sperm count and motility as well as morphologically normal sperm) in men with obesity (169). An obesogenic environment initiates a Th1-lymphocyte and M1-macrophage chronic inflammatory responses that induce pro-inflammatory cytokines and ultimately results in systematic inflammation in the male reproductive system associated with a decrease in immune regulating cells and cytokines (170). Moreover, obesity is identified to be related to increased ROS in semen, which exhibits adverse impacts on the 
quality and function of semen $(171,172)$. Similar impacts of obesity on male reproduction, metabolic syndrome like diabetes mellitus (DM) also disrupt the metabolism of testes that eventually affect spermatogenesis (173).

\section{TARGETING IMMUNOMETABOLISM AS AN ANTI-INFLAMMATORY STRATEGY ON MALE INFERTILITY}

Male reproductive system inflammation like epididymitis and orchitis induced by the immune disorder may be linked to male infertility, or benign hyperplasia, or even cancer. Antibiotic therapies are most commonly used to eradicate infection caused by micro-organisms in the male reproductive system; however, according to the European Association of Urology guidelines, the treatment elicited no positive effect on inflammatory alterations and could not reverse functional deficits and anatomical dysfunction (174). Hence, an appropriate selection of specific anti-inflammatory therapy is urgently needed. Indeed, the relationship between immune and metabolism is bidirectional and includes the integrated role of inflammation in the pathogenesis of metabolic disorders, such as obesity and metabolic syndrome caused by unhealthy lifestyle or systematic diseases, and metabolic factors in the regulation of immune cell functions (175). Collectively, these pieces of evidence suggest that therapies targeting immunometabolism might serve as a novel putative strategy for controlling autoimmunity and inflammation (also can be seen in Table 1).

\section{Antioxidant Therapy}

Excessive ROS production leads to an imbalance of redox and the production of inflammatory cytokines in large amounts (161, 183). Oxidative stress-induced by overproduction of ROS and systematic inflammatory statuses presenting in the body, such as obesity and metabolic syndrome, are associated with male infertility (161). Blocking ROS production is considered as a prior treatment for men with subfertility. Primarily, optimal management strategies, including controlling the elevated inflammatory state and lifestyle modifications with appropriate intervention, are required (170). Adopting a healthy lifestyle, including proper nutritional quality, an appropriate form of physical activity, and effective weight management, represents the most critical strategy to manage metabolic disorders and ensure good health status for male fertility (14). Simultaneous administration of nutraceuticals, such as vitamin $C$, vitamin $E, \beta$ carotenes, magnesium, selenium, zinc, stimulates immune regulating properties (170). In addition, therapeutic drugs, like $\alpha$-lipoic acid, melatonin, coenzyme Q10, pentoxifylline, and lycopene, are also suggested to reduce metabolic disorderrelated inflammatory status in humans (170). These nutraceuticals and drugs that can relieve the inflammatory status present antioxidant properties. Commonly used antioxidants have a positive effect on male fertility, including improvement in basic semen parameters as well as reduction of the levels of ROS and sperm DNA fragment (176). And antioxidants could also improve sperm motility and DNA integrity for infertile men with elevated oxidative stress (177). On the other side, recent randomized controlled trials demonstrated that antioxidants did not improve semen parameters or DNA integrity in infertile men $(184,185)$. The recent Cochrane Review shows that different types as well as treatment time of antioxidants had different effects on sperm parameters (186). The contradictory conclusions of different research about using antioxidant to improve semen quality might partly result from the heterogeneous nature of the study designs, such as the type of antioxidant, dosages, treatment period, sample size, included criteria of participants with either poor semen quality or high level of oxidative stress. However, there is a considerable variability in the reported antioxidant effect on semen parameters and the Cochrane Review was hard to conclude about the effect of antioxidant on improving sperm quality (186). Thus, the outcomes of antioxidant treatment on male subfertility remains controversial. Further studies, especially with larger sample size and well-designed randomized controlled trials, are needed to confirm the effectiveness of antioxidant supplementation on male fertility.

TABLE 1 | Summary of specific anti-inflammatory therapy on male infertility.

\begin{tabular}{|c|c|c|c|c|}
\hline & Management & Consequence & $\begin{array}{l}\text { Successful clinical, pre- } \\
\text { clinical models }\end{array}$ & Reference \\
\hline Antioxidant therapy & $\begin{array}{l}\text { lifestyle modifications; } \\
\text { antioxidant-rich foods intake; } \\
\text { oral antioxidant drug. }\end{array}$ & $\begin{array}{l}\text { reduce the levels of ROS; control the elevated inflammatory } \\
\text { state; reduces the sperm DNA damage; improve sperm } \\
\text { quality and fertility. }\end{array}$ & $\begin{array}{l}\text { oxidative stress; obesity; } \\
\text { metabolic syndrome. }\end{array}$ & $\begin{array}{l}(14,170 \\
176,177)\end{array}$ \\
\hline $\begin{array}{l}\text { Targeting } \\
\text { immunometabolism } \\
\text { therapy }\end{array}$ & $\begin{array}{l}\text { metformin; } \\
\text { rapamycin. }\end{array}$ & $\begin{array}{l}\text { inhibit T cells; promotes memory T cells and tissue-resident } \\
\text { macrophages; reduces chronic inflammation and ROS; } \\
\text { improves insulin sensitivity; increase cholesterol and } \\
\text { triglyceride and fatty acid oxidation; improve sperm quality } \\
\text { and fertility. }\end{array}$ & $\begin{array}{l}\text { T2DM; hyperglycemia; } \\
\text { dyslipidemia. }\end{array}$ & $(178-181)$ \\
\hline Hormone therapy & $\begin{array}{l}\text { testosterone; } \\
\text { aromatase inhibitors. }\end{array}$ & $\begin{array}{l}\text { decreased production of proinflammatory cytokines; } \\
\text { maintained the M2 macrophage phenotype; maintain of } \\
\text { testicular immunosuppressive status. }\end{array}$ & $\begin{array}{l}\text { experimental autoimmune } \\
\text { orchitis. }\end{array}$ & $(82,182)$ \\
\hline
\end{tabular}

ROS, reactive oxygen species; T2DM, type 2 diabetes mellitus. 


\section{Targeting Metabolism for Immune Cell Therapy}

Metformin, a hypoglycaemic medication primarily used as the first-choice treatment for the management of T2DM, reportedly reduces chronic inflammation and ROS directly, and improves insulin sensitivity, hyperglycemia, and dyslipidemia (178). The anti-inflammatory activity of metformin is predominantly mediated by activation of AMPK and inhibition of NF- $\kappa$ B. Upregulation of AMPK stimulated the levels of cholesterol and triglyceride, and fatty acid oxidation, and inactivates acetyl-CoA (the rate-limiting enzyme in the fatty acid synthesis), thus, led to a switch off the anabolic process $(187,188)$. Furthermore, metformin has also been proven to inhibit antigen-induced $\mathrm{T}$ cell proliferation in an AMPK independent manner, and improve impaired B cell function associated with T2DM in vivo, and reduce B cell-intrinsic inflammation in vitro (179, 180). Although the effects of metformin on male productive function and fertility is mainly unclear, human and animal studies have shown that this drug also modulates fertility status and sperm quality, particularly in T2DM, through 1) restoring the structure and weight of testes, epididymis, and seminal vesicles, 2) inhibiting of germ cells apoptosis by enhancing the nutritional function of Sertoli cells to produce, 3 ) increasing sperm count, motility and normal morphology, 4) reducing sperm DNA fragmentation $(188,189)$. However, either in non-diabetic or in non-T2DM conditions, metformin might cause an adverse effect on the male reproductive system (188). Thus, further studies will be needed to clarify what mechanism is involved in this drug's bidirectional action at different statuses.

Moreover, rapamycin-inhibited mTOR restores cellular homeostasis and promotes tolerance and generation of memory $\mathrm{T}$ cells and tissue-resident macrophages (181). Recently, studies have also revealed that in chronic nonbacterial prostatitis models of rats, the activation of the mTOR signaling pathways stimulates inflammatory immune responses by blocking NF- $\kappa \mathrm{B}$ and IL- $1 \beta$ while administration of rapamycin reversed these effects $(190,191)$.

\section{Hormone Therapy}

As mentioned earlier, high testosterone concentration helps maintain a testicular immunosuppressive microenvironment. This is mainly attributed to the suppressed NF- $\mathrm{KB}$ signaling pathway and decreased production of proinflammatory cytokines, leading to sustained M2-like macrophage phenotype, thereby reducing systemic inflammation (82). Due to testosterone's immunosuppressive properties, some researchers have tried to control testosterone in an EAO animal. Furthermore, they found that testosterone treatment significantly attenuates inflammation progression, mediated by blocking the infiltration of inflammatory immune cells and promoting the expansion of competent $\mathrm{CD} 4{ }^{+} \mathrm{CD} 25^{+} \mathrm{Foxp}^{+}$ Tregs in testes $(71,192,193)$. Furthermore, aromatase inhibitors increase testosterone in obese males and improve spermatogenesis and sperm quality; however, significant evidence-based studies on the management of male fertility remain lacking (182). Although the adequate concentration of testosterone is critical for spermatogenesis, excessive testosterone through testosterone therapy generally deteriorates fertility parameters in males via the negative feedback mechanism and should not be used as part of fertility management $(182,194)$.

Based on the immunosuppressive properties of Tregs, drugs that stabilize Tregs (including glucocorticoids and NSAIDs) or drugs used to stimulate Tregs differentiation (such as TGF- $\beta$ and all-trans retinoids) are expected to maximize the benefit of Tregs-based therapies in suppressing autoimmune diseases (138).

\section{COOPERATION OF IMMUNE, ENDOCRINE, AND METABOLISM IN TESTICULAR FUNCTION}

Spermatogenesis is a sophisticatedly complex process and involves a coordinated regulation between endocrine, immune, and metabolism in testes. The complex but methodical coregulation is benefited from the multiplied cell interactions, although BTB separates these cells. As mentioned above, testosterone produced by Leydig cells and are controlled through LH produced in the hypothalamus plays a critical role in the maintenance of immunosuppressive microenvironment for normal spermatogenesis within testes through maintaining regulatory macrophage phenotype and function, inducing $\mathrm{CD} 4{ }^{+} \mathrm{CD} 25^{+} \mathrm{Foxp}^{+}$Tregs expansion, and meanwhile inhibiting $\mathrm{CD}^{+}$and $\mathrm{CD}^{+} \mathrm{T}$ cells activation. In turn, $\mathrm{T}$ lymphocyte infiltration would decrease Leydig cell population during inflammation resulting from LPS stimulation and virus infection (such as coronavirus disease 2019), whereas the number of Leydig cell would be recovered in $\alpha \beta, \gamma \delta$, and CD8 lymphocytes deficient mice (195-197). Macrophage numbers was also significantly decline after Leydig cells were destroyed or the function of Leydig cells were inhibited $(84,198)$. This might imply that there was relationship between the number of Leydig cells with Macrophage, and T lymphocytes. On the other hand, testosterone is also bound to AR in Sertoli cells to regulate the expression of the spermatogenesis-related gene and regulate glucose metabolism. Furthermore, FSH, acting as the master endocrine regulator of Sertoli cells, stimulated lactate production by Sertoli cells in a HIF-dependent manner (199). Since developing germ cells cannot synthesize lactate, Sertoli cells would converse $75 \%$ of their pyruvate production into lactate or pyruvate to fulfill germ cells (200). Tumor cells induced the M2 macrophage phenotype by producing a high lactate level (108). However, there is a doubt whether Sertoli cells-produced lactate would induce immunosuppressive macrophage in testes. Testicular FAO metabolism, particularly PGs production via COX2, was controlled by $\mathrm{LH}, \mathrm{FSH}$, androgens, and prolactin (106). In turn, PGs acted as an autocrine regulator of Leydig cell steroidogenesis and Sertoli cell function and indirectly regulated sperm maturation (106).

Although the effect of metabolism on testicular immune homeostasis is less clear, the data from either immunologically privileged sites like tumor tissue and pregnant uterus or some normal tissue except testes have been shown that metabolic 
reprogramming is necessary for the polarization and activation of immune cells, as mentioned above. For example, oxidative metabolism, such as OXPHOS and FAO pathway, generally markedly increased to promote the immunologically tolerant phenotypes of macrophages, DCs, Tregs, and regulatory NK cells. Conversely, the activation of these immune cells needs higher anaerobic metabolism to meet the rapid energy requirements and produce proinflammatory cytokines, like IL6 , NO, and TNF- $\alpha$. In this context, it is unquestionable that metabolic reprogramming also plays a vital role in the immunologically privileged characterization of the testis, which remains to be further investigated in subsequent studies. In supporting this, the concentration of testosterone and PGs in testes was higher than in peripheral blood, both of which were synthesized through lipid metabolism by testicular somatic cells. These molecules displayed an immunosuppressive effect on macrophages and T lymphocytes. For example, Sertoli cells act as immunological sentinels of spermatogenesis in partial by forming metabolites, such as PGs, IDO to polarize M2 macrophage and inhibit T and NK cells, respectively $(81,106)$. On the other hand, when the body suffers from systematic metabolic, the immune homeostasis required for the normal spermatogenesis process will be disturbed. The metabolic disbalance leads to male hypogonadism as well as dysfunction of testicular environment for spermatogenesis. Metabolic disorder with adipose tissue increases the conversion of testosterone to $17 \beta$-estradiol and promotes feedback at HTP axis, inhibiting the secretion of both FSH and $\mathrm{LH}$, and finally impairs spermatogenesis (201). This suppression of HPT induced by adipose tissue might be mediated via dysregulated leptin signaling and pro-inflammatory cytokines (202). Moreover, obesity and metabolic syndrome, accompanied by excessive fat deposition on the scrotal area, would trigger proinflammatory status once adipocytes rupture and ultimately disrupt the spermatogenesis (203). Additionally, a recent experiment revealed that high-fat diet not only induced significant more body weight than their age-matched littermates fed but also impair spermatogenesis by altering glucose and lipid metabolism in Sertoli cells, which lead to Sertoli cells dysfunction and ultimately decreased sperm quality (204). Collectively, the interactions between endocrine,

\section{REFERENCES}

1. Ashrafzadeh A, Karsani SA, Nathan S. Mammalian Sperm Fertility Related Proteins. Int J Med Sci (2013) 10(12):1649-57. doi: 10.7150/ijms.6395

2. Haschek WM, Rousseaux CG, Wallig MA. "Chapter 18 - Male Reproductive System”. In: WM Haschek, CG Rousseaux and MA Wallig, editors. Fundamentals of Toxicologic Pathology (Second Edition), vol. 553-597. San Diego: Academic Press (2010).

3. Diemer $\mathrm{T}$, Hales $\mathrm{DB}$, Weidner W. Immune-Endocrine Interactions and Leydig Cell Function: The Role of Cytokines. Andrologia (2003) 35(1):5563. doi: 10.1046/j.1439-0272.2003.00537.x

4. Dhole B, Kumar A. "Hypothalamic-Pituitary-Testicular Axis". In: Basics of Human Andrology. Singapore: Springer (2017). p. 117-34.

5. Hermann BP, Cheng K, Singh A, Roa-De La Cruz L, Mutoji KN, Chen IC, et al. The Mammalian Spermatogenesis Single-Cell Transcriptome, From immune and metabolism are essential to maintain the immune environment of the testis and the proper nutrient concentration for the spermatogenic process.

\section{CONCLUSIONS}

In summary, the regulation of male reproduction by the HPT axis is, at least in part, through the immune system. The immune cells effectively provide the immunocompetent microenvironment for normal spermatogenesis and subsequent processes, such as sperm maturation. The immune cells develop, activate, and differentiate into unique phenotypes and function in response to the synergistic effects of HPT axis-regulated hormones and the immune microenvironment of the reproductive system. In turn, the metabolic reprogramming of immune cells plays a pivotal role in supporting and modeling the immune microenvironment. There is accumulating appreciation for the part of metabolic alterations in the functions of immune cells. However, the role of immunometabolism on male fertility and whether the HPT axis engages in switching the metabolic flux of immune cells remain to be elucidated. With a well-established understanding of metabolism and immunity, it would be interesting to explore immunometabolism further to clarify the conceptual framework for male reproductive health.

\section{AUTHOR CONTRIBUTIONS}

LY and WH have contributed equally to this work. All authors contributed to the article and approved the submitted version.

\section{FUNDING}

This review is made possible through the support of the National Key R\&D Program of China (2018YFC1003900/ 2018YFC1003904), Shenzhen Natural Science Foundation (JCYJ20190813161801676) to LD, the German Research Foundation to KT (TH 2126/1-1), and Sanming Project of Medicine in Shenzhen (SZSM201502035).
Spermatogonial Stem Cells to Spermatids. Cell Rep (2018) 25(6):1650-1667 e1658. doi: 10.1016/j.celrep.2018.10.026

6. Fijak M, Meinhardt A. The Testis in Immune Privilege. Immunol Rev (2006) 213:66-81. doi: 10.1111/j.1600-065X.2006.00438.x

7. Arck P, Solano ME, Walecki M, Meinhardt A. The Immune Privilege of Testis and Gravid Uterus: Same Difference? Mol Cell Endocrinol (2014) 382 (1):509-20. doi: 10.1016/j.mce.2013.09.022

8. Stanton PG. Regulation of the Blood-Testis Barrier. Semin Cell Dev Biol (2016) 59:166-73. doi: 10.1016/j.semcdb.2016.06.018

9. Zhao S, Zhu W, Xue S, Han D. Testicular Defense Systems: Immune Privilege and Innate Immunity. Cell Mol Immunol (2014) 11(5):428-37. doi: $10.1038 / \mathrm{cmi} .2014 .38$

10. Meinhardt A, Hedger MP. Immunological, Paracrine and Endocrine Aspects of Testicular Immune Privilege. Mol Cell Endocrinol (2011) 335(1):60-8. doi: 10.1016/j.mce.2010.03.022 
11. Schuppe H, Meinhardt A. Immune Privilege and Inflammation of the Testis. Chem Immunol Allergy (2005) 88:1-14. doi: 10.1159/000087816

12. Jacobo P, Guazzone VA, Theas MS, Lustig L. Testicular Autoimmunity. Autoimmun Rev (2011) 10(4):201-4. doi: 10.1016/j.autrev.2010.09.026

13. Chen Q, Deng T, Han D. Testicular Immunoregulation and Spermatogenesis. Semin Cell Dev Biol (2016) 59:157-65. doi: 10.1016/ j.semcdb.2016.01.019

14. Martins AD, Majzoub A, Agawal A. Metabolic Syndrome and Male Fertility. World J Mens Health (2019) 37(2):113-27. doi: 10.5534/wjmh.180055

15. Cheng CY, Wong EW, Yan HH, Mruk DD. Regulation of Spermatogenesis in the Microenvironment of the Seminiferous Epithelium: New Insights and Advances. Mol Cell Endocrinol (2010) 315(1-2):49-56. doi: 10.1016/ j.mce.2009.08.004

16. Oliveira PF, Alves MG. "Testicular Metabolic Cooperation”. In: Sertoli Cell Metabolism and Spermatogenesis. Cham: Springer International Publishing (2015).

17. Dias T R, Martins A D, Reis V P, Socorro S M, Silva B, Alves M G, et al. Glucose Transport and Metabolism in Sertoli Cell: Relevance for Male Fertility. Curr Chem Biol (2014) 7(3):282-93. doi: 10.2174/ 2212796807999131128125510

18. Rato L, Alves MG, Socorro S, Duarte AI, Cavaco JE, Oliveira PF. Metabolic Regulation is Important for Spermatogenesis. Nat Rev Urol (2012) 9(6):3308. doi: $10.1038 /$ nrurol.2012.77

19. Li N, Wang T, Han D. Structural, Cellular and Molecular Aspects of Immune Privilege in the Testis. Front Immunol (2012) 3:152. doi: 10.3389/ fimmu.2012.00152

20. Kaur G, Thompson LA, Dufour JM. Sertoli Cells-Immunological Sentinels of Spermatogenesis. Semin Cell Dev Biol (2014) 30:36-44. doi: 10.1016/ j.semcdb.2014.02.011

21. Boussouar F, Benahmed M. Lactate and Energy Metabolism in Male Germ Cells. Trends Endocrinol Metab (2004) 15(7):345-50. doi: 10.1016/ j.tem.2004.07.003

22. Franca LR, Hess RA, Dufour JM, Hofmann MC, Griswold MD. The Sertoli Cell: One Hundred Fifty Years of Beauty and Plasticity. Andrology (2016) 4 (2):189-212. doi: 10.1111/andr.12165

23. Jankovic Velickovic L, Stefanovic V. Hypoxia and Spermatogenesis. Int Urol Nephrol (2014) 46(5):887-94. doi: 10.1007/s11255-013-0601-1

24. Doyle TJ, Kaur G, Putrevu SM, Dyson EL, Dyson M, McCunniff WT, et al. Immunoprotective Properties of Primary Sertoli Cells in Mice: Potential Functional Pathways That Confer Immune Privilegel. Biol Reprod (2012) 86 (1):1-14. doi: 10.1095/biolreprod.110.089425

25. Holdcraft RW, Braun RE. Hormonal Regulation of Spermatogenesis. Int $J$ Androl (2004) 27(6):335-42. doi: 10.1111/j.1365-2605.2004.00502.x

26. Zirkin BR, Papadopoulos V. Leydig Cells: Formation, Function, and Regulation. Biol Reprod (2018) 99(1):101-11. doi: 10.1093/biolre/ioy059

27. Smith LB, Walker WH. The Regulation of Spermatogenesis by Androgens. Semin Cell Dev Biol (2014) 30:2-13. doi: 10.1016/j.semcdb.2014.02.012

28. Hedger MP. "The Immunophysiology of Male Reproduction". In: Knobil and Neill's Physiology of Reproduction. San Diego: Academic Press (2015).

29. Qu N, Ogawa Y, Kuramasu M, Nagahori K, Sakabe K, Itoh M. Immunological Microenvironment in the Testis. Reprod Med Biol (2020) 19(1):24-31. doi: 10.1002/rmb2.12293

30. Newton R, Priyadharshini B, Turka LA. Immunometabolism of Regulatory T Cells. Nat Immunol (2016) 17(6):618-25. doi: 10.1038/ni.3466

31. Van den Bossche J, O'Neill LA, Menon D. Macrophage Immunometabolism: Where Are We (Going)? Trends Immunol (2017) 38(6):395-406. doi: 10.1016/j.it.2017.03.001

32. Pearce EJ, O'Neill LAJ. Immunometabolism Governs Dendritic Cell and Macrophage Function. J Exp Med (2016) 213(1):15-23. doi: 10.1084/ jem. 20151570

33. Poznanski SM, Barra NG, Ashkar AA, Schertzer JD. Immunometabolism of T Cells and NK Cells: Metabolic Control of Effector and Regulatory Function. Inflammation Res (2018) 67(10):813-28. doi: 10.1007/s00011-018-1174-3

34. Mathis D, Shoelson SE. Immunometabolism: An Emerging Frontier. Nat Rev Immunol (2011) 11(2):81. doi: 10.1038/nri2922

35. Eaton SA, Sethi JK. Immunometabolic Links Between Estrogen, Adipose Tissue and Female Reproductive Metabolism. Biol (Basel) (2019) 8(1):8. doi: 10.3390/biology 8010008
36. Thiele K, Diao L, Arck PC. Immunometabolism, Pregnancy, and Nutrition. Semin Immunopathol (2018) 40(2):157-74. doi: 10.1007/s00281-017-0660-y

37. Pearce EJ, Pearce EL. Immunometabolism in 2017: Driving Immunity: All Roads Lead to Metabolism. Nat Rev Immunol (2018) 18(2):81-2. doi: 10.1038/nri.2017.139

38. O'Neill LA, Kishton RJ, Rathmell J. A Guide to Immunometabolism for Immunologists. Nat Rev Immunol (2016) 16(9):553-65. doi: 10.1038/ nri.2016.70

39. Stathopoulou C, Nikoleri D, Bertsias G. Immunometabolism: An Overview and Therapeutic Prospects in Autoimmune Diseases. Immunotherapy (2019) 11(9):813-29. doi: 10.2217/imt-2019-0002

40. Plant TM. 60 YEARS OF NEUROENDOCRINOLOGY: The HypothalamoPituitary-Gonadal Axis. J Endocrinol (2015) 226(2):T41-54. doi: 10.1530/ JOE-15-0113

41. Ramaswamy S, Weinbauer GF. Endocrine Control of Spermatogenesis: Role of FSH and LH/testosterone. Spermatogenesis (2014) 4(2):e996025. doi: 10.1080/21565562.2014.996025

42. Huhtaniemi I, Teerds K. "Leydig Cells". In: Encyclopedia of Reproduction. Oxford: Academic Press (2018).

43. Meinhardt A, Bacher M, McFarlane JR, Metz CN, Seitz J, Hedger MP, et al. Macrophage Migration Inhibitory Factor Production by Leydig Cells: Evidence for a Role in the Regulation of Testicular Function. Endocrinology (1996) 137(11):5090-5. doi: 10.1210/endo.137. 11.8895383

44. Meccariello R, Chianese R, Chioccarelli T, Ciaramella V, Fasano S, Pierantoni R, et al. Intra-Testicular Signals Regulate Germ Cell Progression and Production of Qualitatively Mature Spermatozoa in Vertebrates. Front Endocrinol (Lausanne) (2014) 5:69. doi: 10.3389/ fendo.2014.00069

45. Oliveira PF, Alves MG. "Modulation of Sertoli Cell Metabolism". In: Sertoli Cell Metabolism and Spermatogenesis. Cham: Springer International Publishing (2015).

46. Rato L, Meneses MJ, Silva BM, Sousa M, Alves MG, Oliveira PF. New Insights on Hormones and Factors That Modulate Sertoli Cell Metabolism. Histol Histopathol (2016) 31(5):499-513. doi: 10.14670/HH-11-717

47. Guma FC, Wagner M, Martini LH, Bernard EA. Effect of FSH and Insulin on Lipogenesis in Cultures of Sertoli Cells From Immature Rats. Braz J Med Biol Res (1997) 30(5):591-7. doi: 10.1590/s0100-879x1997000500004

48. Oliveira PF, Alves MG, Rato L, Silva J, Sa R, Barros A, et al. Influence of 5alpha-Dihydrotestosterone and 17beta-Estradiol on Human Sertoli Cells Metabolism. Int J Androl (2011) 34(6 Pt 2):e612-20. doi: 10.1111/j.13652605.2011.01205.x

49. Raut S, Kumar AV, Deshpande S, Khambata K, Balasinor NH. Sex Hormones Regulate Lipid Metabolism in Adult Sertoli Cells: A GenomeWide Study of Estrogen and Androgen Receptor Binding Sites. J Steroid Biochem Mol Biol (2021) 211:105898. doi: 10.1016/j.jsbmb.2021.105898

50. Alves MG, Rato L, Carvalho RA, Moreira PI, Socorro S, Oliveira PF. Hormonal Control of Sertoli Cell Metabolism Regulates Spermatogenesis. Cell Mol Life Sci (2013) 70(5):777-93. doi: 10.1007/s00018-012-1079-1

51. Bhatia A, Sekhon HK, Kaur G. Sex Hormones and Immune Dimorphism. ScientificWorldJournal (2014) 2014:159150. doi: 10.1155/2014/159150

52. Tsigos C, Chrousos GP. Hypothalamic-Pituitary-Adrenal Axis, Neuroendocrine Factors and Stress. J Psychosom Res (2002) 53(4):865-71. doi: 10.1016/s0022-3999(02)00429-4

53. Segner H, Verburg-van Kemenade BML, Chadzinska M. The Immunomodulatory Role of the Hypothalamus-Pituitary-Gonad Axis: Proximate Mechanism for Reproduction-Immune Trade Offs? Dev Comp Immunol (2017) 66:43-60. doi: 10.1016/j.dci.2016.07.004

54. Standaert FE, Chew BP, De Avila D, Reeves JJ. Presence of Luteinizing Hormone-Releasing Hormone Binding Sites in Cultured Porcine Lymphocytes. Biol Reprod (1992) 46(6):997-1000. doi: 10.1095/ biolreprod46.6.997

55. Tanriverdi F, Gonzalez-Martinez D, Silveira LF, Hu Y, Maccoll GS, Travers $\mathrm{P}$, et al. Expression of Gonadotropin-Releasing Hormone Type-I (GnRH-I) and Type-II (GnRH-II) in Human Peripheral Blood Mononuclear Cells (PMBCs) and Regulation of B-Lymphoblastoid Cell Proliferation by GnRHI and GnRH-II. Exp Clin Endocrinol Diabetes (2004) 112(10):587-94. doi: 10.1055/s-2004-830404 
56. Chen H-F, Jeung E-B, Stephenson M, Leung PCK. Human Peripheral Blood Mononuclear Cells Express Gonadotropin-Releasing Hormone (GnRH), GnRH Receptor, and Interleukin-2 Receptor $\gamma$-Chain Messenger Ribonucleic Acids That Are Regulated by GnRH In Vitro1. J Clin Endocrinol Metab (1999) 84(2):743-50. doi: 10.1210/jcem.84.2.5440

57. Morale MC, Batticane N, Bartoloni G, Guarcello V, Farinella Z, Galasso MG, et al. Blockade of Central and Peripheral Luteinizing Hormone-Releasing Hormone (LHRH) Receptors in Neonatal Rats With a Potent LHRHAntagonist Inhibits the Morphofunctional Development of the Thymus and Maturation of the Cell-Mediated and Humoral Immune Responses. Endocrinology (1991) 128(2):1073-85. doi: 10.1210/endo-128-2-1073

58. Mann DR, Howie S, Paulsen DF, Akinbami MA, Lunn SF, Fraser HM. Changes in Lymphoid Tissue After Treatment With a Gonadotropin Releasing Hormone Antagonist in the Neonatal Marmoset (Callithrix Jacchus). Am J Reprod Immunol (1998) 39(4):256-65. doi: 10.1111/j.16000897.1998.tb00362.x

59. Tanriverdi F, Silveira LF, MacColl GS, Bouloux PM. The HypothalamicPituitary-Gonadal Axis: Immune Function and Autoimmunity. J Endocrinol (2003) 176(3):293-304. doi: 10.1677/joe.0.1760293

60. Weigent DA, Blalock JE. Associations Between the Neuroendocrine and Immune Systems. J Leukocyte Biol (1995) 58(2):137-50. doi: 10.1002/ jlb.58.2.137

61. Carbone F, Procaccini C, De Rosa V, Alviggi C, De Placido G, Kramer D, et al. Divergent Immunomodulatory Effects of Recombinant and UrinaryDerived FSH, LH, and hCG on Human CD4+ T Cells. J Reprod Immunol (2010) 85(2):172-9. doi: 10.1016/j.jri.2010.02.009

62. Yesilova Z, Ozata M, Kocar IH, Turan M, Pekel A, Sengul A, et al. The Effects of Gonadotropin Treatment on the Immunological Features of Male Patients With Idiopathic Hypogonadotropic Hypogonadism. J Clin Endocrinol Metab (2000) 85(1):66-70. doi: 10.1210/jcem.85.1.6226

63. Bouman A, Heineman MJ, Faas MM. Sex Hormones and the Immune Response in Humans. Hum Reprod Update (2005) 11(4):411-23. doi: $10.1093 /$ humupd/dmi008

64. Kovats S. Estrogen Receptors Regulate Innate Immune Cells and Signaling Pathways. Cell Immunol (2015) 294(2):63-9. doi: 10.1016/j.cellimm. 2015.01.018

65. Klein SL, Flanagan KL. Sex Differences in Immune Responses. Nat Rev Immunol (2016) 16(10):626-38. doi: 10.1038/nri.2016.90

66. Roved J, Westerdahl H, Hasselquist D. Sex Differences in Immune Responses: Hormonal Effects, Antagonistic Selection, and Evolutionary Consequences. Horm Behav (2017) 88:95-105. doi: 10.1016/j.yhbeh. 2016.11.017

67. Trigunaite A, Dimo J, Jorgensen TN. Suppressive Effects of Androgens on the Immune System. Cell Immunol (2015) 294(2):87-94. doi: 10.1016/ j.cellimm.2015.02.004

68. Ysrraelit MC, Correale J. Impact of Sex Hormones on Immune Function and Multiple Sclerosis Development. Immunology (2019) 156(1):9-22. doi: $10.1111 / \mathrm{imm} .13004$

69. Traish A, Bolanos J, Nair S, Saad F, Morgentaler A. Do Androgens Modulate the Pathophysiological Pathways of Inflammation? Appraising the Contemporary Evidence. J Clin Med (2018) 7(12):549. doi: 10.3390/ jcm7120549

70. Meng J, Greenlee AR, Taub CJ, Braun RE. Sertoli Cell-Specific Deletion of the Androgen Receptor Compromises Testicular Immune Privilege in Mice. Biol Reprod (2011) 85(2):254-60. doi: 10.1095/biolreprod.110.090621

71. Fijak M, Schneider E, Klug J, Bhushan S, Hackstein H, Schuler G, et al. Testosterone Replacement Effectively Inhibits the Development of Experimental Autoimmune Orchitis in Rats: Evidence for a Direct Role of Testosterone on Regulatory T Cell Expansion. J Immunol (2011) 186 (9):5162-72. doi: 10.4049/jimmunol.1001958

72. Walecki M, Eisel F, Klug J, Baal N, Paradowska-Dogan A, Wahle E, et al. Androgen Receptor Modulates Foxp3 Expression in CD4+CD25+Foxp3+ Regulatory T-Cells. Mol Biol Cell (2015) 26(15):2845-57. doi: 10.1091/ mbc.E14-08-1323

73. Fijak M, Damm LJ, Wenzel JP, Aslani F, Walecki M, Wahle E, et al. Influence of Testosterone on Inflammatory Response in Testicular Cells and Expression of Transcription Factor Foxp3 in T Cells. Am J Reprod Immunol (2015) 74(1):12-25. doi: 10.1111/aji.12363
74. Cunningham M, Gilkeson G. Estrogen Receptors in Immunity and Autoimmunity. Clin Rev Allergy Immunol (2011) 40(1):66-73. doi: 10.1007/s12016-010-8203-5

75. Giefing-Kröll C, Berger P, Lepperdinger G, Grubeck-Loebenstein B. How Sex and Age Affect Immune Responses, Susceptibility to Infections, and Response to Vaccination. Aging Cell (2015) 14(3):309-21. doi: 10.1111/ acel. 12326

76. Fish EN. The X-Files in Immunity: Sex-Based Differences Predispose Immune Responses. Nat Rev Immunol (2008) 8(9):737-44. doi: 10.1038/ nri2394

77. Cooke PS, Nanjappa MK, Ko C, Prins GS, Hess RA. Estrogens in Male Physiology. Physiol Rev (2017) 97(3):995-1043. doi: 10.1152/ physrev.00018.2016

78. Winn NC, Jurrissen TJ, Grunewald ZI, Cunningham RP, Woodford ML, Kanaley JA, et al. Estrogen Receptor-Alpha Signaling Maintains Immunometabolic Function in Males and is Obligatory for ExerciseInduced Amelioration of Nonalcoholic Fatty Liver. Am J Physiol Endocrinol Metab (2019) 316(2):E156-67. doi: 10.1152/ajpendo.00259.2018

79. Yu W, Zheng H, Lin W, Tajima A, Zhang Y, Zhang X, et al. Estrogen Promotes Leydig Cell Engulfment by Macrophages in Male Infertility. J Clin Invest (2014) 124(6):2709-21. doi: 10.1172/JCI59901

80. Lustig L, Lourtau L, Perez R, Doncel GF. Phenotypic Characterization of Lymphocytic Cell Infiltrates Into the Testes of Rats Undergoing Autoimmune Orchitis. Int J Androl (1993) 16(4):279-84. doi: 10.1111/ j.1365-2605.1993.tb01192.x

81. Wang M, Fijak M, Hossain H, Markmann M, Nusing RM, Lochnit G, et al. Characterization of the Micro-Environment of the Testis That Shapes the Phenotype and Function of Testicular Macrophages. J Immunol (2017) 198 (11):4327-40. doi: 10.4049/jimmunol.1700162

82. Meinhardt A, Wang M, Schulz C, Bhushan S. Microenvironmental Signals Govern the Cellular Identity of Testicular Macrophages. J Leukoc Biol (2018) 104(4):757-66. doi: 10.1002/JLB.3MR0318-086RR

83. Winnall WR, Hedger MP. Phenotypic and Functional Heterogeneity of the Testicular Macrophage Population: A New Regulatory Model. J Reprod Immunol (2013) 97(2):147-58. doi: 10.1016/j.jri.2013.01.001

84. Wang J, Wreford NG, Lan HY, Atkins R, Hedger MP. Leukocyte Populations of the Adult Rat Testis Following Removal of the Leydig Cells by Treatment With Ethane Dimethane Sulfonate and Subcutaneous Testosterone Implants. Biol Reprod (1994) 51(3):551-61. doi: 10.1095/ biolreprod51.3.551

85. Ponte R, Dupuy FP, Brimo F, Mehraj V, Brassard P, Belanger M, et al. Characterization of Myeloid Cell Populations in Human Testes Collected After Sex Reassignment Surgery. J Reprod Immunol (2018) 125:16-24. doi: 10.1016/j.jri.2017.10.043

86. Pollanen P, Niemi M. Immunohistochemical Identification of Macrophages, Lymphoid Cells and HLA Antigens in the Human Testis. Int J Androl (1987) 10(1):37-42. doi: 10.1111/j.1365-2605.1987.tb00163.x

87. Mossadegh-Keller N, Gentek R, Gimenez G, Bigot S, Mailfert S, Sieweke MH. Developmental Origin and Maintenance of Distinct Testicular Macrophage Populations. J Exp Med (2017) 214(10):2829-41. doi: 10.1084/jem.20170829

88. Wang M, Yang Y, Cansever D, Wang Y, Kantores C, Messiaen S, et al. Two Populations of Self-Maintaining Monocyte-Independent Macrophages Exist in Adult Epididymis and Testis. Proc Natl Acad Sci USA (2021) 118(1): e2013686117. doi: 10.1073/pnas.2013686117

89. Yee JB, Hutson JC. Effects of Testicular Macrophage-Conditioned Medium on Leydig Cells in Culture. Endocrinology (1985) 116(6):2682-4. doi: 10.1210/endo-116-6-2682

90. Nes WD, Lukyanenko YO, Jia ZH, Quideau S, Howald WN, Pratum TK, et al. Identification of the Lipophilic Factor Produced by Macrophages That Stimulates Steroidogenesis. Endocrinology (2000) 141(3):953-8. doi: 10.1210/endo.141.3.7350

91. Cohen PE, Chisholm O, Arceci RJ, Stanley ER, Pollard JW. Absence of Colony-Stimulating Factor-1 in Osteopetrotic (Csfmop/Csfmop) Mice Results in Male Fertility Defects. Biol Reprod (1996) 55(2):310-7. doi: 10.1095/biolreprod55.2.310

92. Gaytan F, Bellido C, Morales C, Reymundo C, Aguilar E, Van Rooijen N. Effects of Macrophage Depletion at Different Times After Treatment With 
Ethylene Dimethane Sulfonate (EDS) on the Regeneration of Leydig Cells in the Adult Rat. J Androl (1994) 15(6):558-64. doi: 10.1002/j.19394640.1994.tb00499.x

93. O'Hara L, Smith LB. Androgen Receptor Roles in Spermatogenesis and Infertility. Best Pract Res Clin Endocrinol Metab (2015) 29(4):595-605. doi: 10.1016/j.beem.2015.04.006

94. Toocheck C, Clister T, Shupe J, Crum C, Ravindranathan P, Lee TK, et al. Mouse Spermatogenesis Requires Classical and Nonclassical Testosterone Signaling. Biol Reprod (2016) 94(1):11. doi: 10.1095/biolreprod.115.132068

95. Rato L, Alves MG, Socorro S, Carvalho RA, Cavaco JE, Oliveira PF. Metabolic Modulation Induced by Oestradiol and DHT in Immature Rat Sertoli Cells Cultured In Vitro. Biosci Rep (2012) 32(1):61-9. doi: 10.1042/ BSR20110030

96. Martins AD, Alves MG, Simoes VL, Dias TR, Rato L, Moreira PI, et al. Control of Sertoli Cell Metabolism by Sex Steroid Hormones is Mediated Through Modulation in Glycolysis-Related Transporters and Enzymes. Cell Tissue Res (2013) 354(3):861-8. doi: 10.1007/s00441-013-1722-7

97. Grootegoed JA, Oonk RB, Jansen R, van der Molen HJ. Metabolism of Radiolabelled Energy-Yielding Substrates by Rat Sertoli Cells. J Reprod Fertil (1986) 77(1):109-18. doi: 10.1530/jrf.0.0770109

98. DeFalco T, Potter SJ, Williams AV, Waller B, Kan MJ, Capel B. Macrophages Contribute to the Spermatogonial Niche in the Adult Testis. Cell Rep (2015) 12(7):1107-19. doi: 10.1016/j.celrep.2015.07.015

99. Winnall WR, Muir JA, Hedger MP. Rat Resident Testicular Macrophages Have an Alternatively Activated Phenotype and Constitutively Produce Interleukin-10 In Vitro. J Leukoc Biol (2011) 90(1):133-43. doi: 10.1189/ jlb.1010557

100. Bhushan S, Tchatalbachev S, Lu Y, Frohlich S, Fijak M, Vijayan V, et al. Differential Activation of Inflammatory Pathways in Testicular Macrophages Provides a Rationale for Their Subdued Inflammatory Capacity. J Immunol (2015) 194(11):5455-64. doi: 10.4049/jimmunol.1401132

101. Bhushan S, Meinhardt A. The Macrophages in Testis Function. J Reprod Immunol (2017) 119:107-12. doi: 10.1016/j.jri.2016.06.008

102. Newsholme P, Gordon S, Newsholme EA. Rates of Utilization and Fates of Glucose, Glutamine, Pyruvate, Fatty Acids and Ketone Bodies by Mouse Macrophages. Biochem J (1987) 242(3):631-6. doi: 10.1042/bj2420631

103. Jha AK, Huang SC, Sergushichev A, Lampropoulou V, Ivanova Y, Loginicheva E, et al. Network Integration of Parallel Metabolic and Transcriptional Data Reveals Metabolic Modules That Regulate Macrophage Polarization. Immunity (2015) 42(3):419-30. doi: 10.1016/ j.immuni.2015.02.005

104. Vats D, Mukundan L, Odegaard JI, Zhang L, Smith KL, Morel CR, et al. Oxidative Metabolism and PGC-1beta Attenuate Macrophage-Mediated Inflammation. Cell Metab (2006) 4(1):13-24. doi: 10.1016/j.cmet.2006.05.011

105. Odegaard JI, Chawla A. Alternative Macrophage Activation and Metabolism. Annu Rev Pathol (2011) 6:275-97. doi: 10.1146/annurev-pathol-011110130138

106. Frungieri MB, Calandra RS, Mayerhofer A, Matzkin ME. Cyclooxygenase and Prostaglandins in Somatic Cell Populations of the Testis. Reproduction (2015) 149(4):R169-180. doi: 10.1530/REP-14-0392

107. Leone RD, Powell JD. Metabolism of Immune Cells in Cancer. Nat Rev Cancer (2020) 20(9):516-31. doi: 10.1038/s41568-020-0273-y

108. Colegio OR, Chu NQ, Szabo AL, Chu T, Rhebergen AM, Jairam V, et al. Functional Polarization of Tumour-Associated Macrophages by TumourDerived Lactic Acid. Nature (2014) 513(7519):559-63. doi: 10.1038/ nature 13490

109. Zhu L, Zhao Q, Yang T, Ding W, Zhao Y. Cellular Metabolism and Macrophage Functional Polarization. Int Rev Immunol (2015) 34(1):82100. doi: 10.3109/08830185.2014.969421

110. Wang P, Duan YG. The Role of Dendritic Cells in Male Reproductive Tract. Am J Reprod Immunol (2016) 76(3):186-92. doi: 10.1111/aji.12536

111. Malinarich F, Duan K, Hamid RA, Bijin A, Lin WX, Poidinger M, et al. High Mitochondrial Respiration and Glycolytic Capacity Represent a Metabolic Phenotype of Human Tolerogenic Dendritic Cells. J Immunol (2015) 194 (11):5174-86. doi: 10.4049/jimmunol.1303316

112. O'Neill LA, Pearce EJ. Immunometabolism Governs Dendritic Cell and Macrophage Function. J Exp Med (2016) 213(1):15-23. doi: 10.1084/ jem. 20151570
113. Ferreira GB, Vanherwegen AS, Eelen G, Gutierrez ACF, Van Lommel L, Marchal K, et al. Vitamin D3 Induces Tolerance in Human Dendritic Cells by Activation of Intracellular Metabolic Pathways. Cell Rep (2015) 10 (5):711-25. doi: 10.1016/j.celrep.2015.01.013

114. Mellor AL, Munn DH. IDO Expression by Dendritic Cells: Tolerance and Tryptophan Catabolism. Nat Rev Immunol (2004) 4(10):762-74. doi: $10.1038 /$ nri1457

115. Liu Y, Liang X, Dong W, Fang Y, Lv J, Zhang T, et al. Tumor-Repopulating Cells Induce PD-1 Expression in CD8(+) T Cells by Transferring Kynurenine and AhR Activation. Cancer Cell (2018) 33480-94(3):e487. doi: 10.1016/j.ccell.2018.02.005

116. Mezrich JD, Fechner JH, Zhang X, Johnson BP, Burlingham WJ, Bradfield CA. An Interaction Between Kynurenine and the Aryl Hydrocarbon Receptor can Generate Regulatory T Cells. J Immunol (2010) 185(6):31908. doi: 10.4049/jimmunol.0903670

117. Pallotta MT, Orabona C, Volpi C, Vacca C, Belladonna ML, Bianchi R, et al. Indoleamine 2,3-Dioxygenase is a Signaling Protein in Long-Term Tolerance by Dendritic Cells. Nat Immunol (2011) 12(9):870-8. doi: 10.1038/ni.2077

118. Munn DH, Mellor AL. Indoleamine 2,3-Dioxygenase and Tumor-Induced Tolerance. J Clin Invest (2007) 117(5):1147-54. doi: 10.1172/JCI31178

119. Munn DH, Zhou M, Attwood JT, Bondarev I, Conway SJ, Marshall B, et al. Prevention of Allogeneic Fetal Rejection by Tryptophan Catabolism. Science (1998) 281(5380):1191-3. doi: 10.1126/science.281.5380.1191

120. Gualdoni GS, Jacobo PV, Sobarzo CM, Perez CV, Matzkin ME, Hocht C, et al. Role of Indoleamine 2,3-Dioxygenase in Testicular Immune-Privilege. Sci Rep (2019) 9(1):15919. doi: 10.1038/s41598-019-52192-8

121. Chen Z, Gordon JR, Zhang X, Xiang J. Analysis of the Gene Expression Profiles of Immature Versus Mature Bone Marrow-Derived Dendritic Cells Using DNA Arrays. Biochem Biophys Res Commun (2002) 290(1):66-72. doi: 10.1006/bbrc.2001.6147

122. Romani L, Fallarino F, De Luca A, Montagnoli C, D’Angelo C, Zelante T, et al. Defective Tryptophan Catabolism Underlies Inflammation in Mouse Chronic Granulomatous Disease. Nature (2008) 451(7175):211-5. doi: $10.1038 /$ nature 06471

123. Gandaglia G, Briganti A, Gontero P, Mondaini N, Novara G, Salonia A, et al. The Role of Chronic Prostatic Inflammation in the Pathogenesis and Progression of Benign Prostatic Hyperplasia (BPH). BJU Int (2013) 112 (4):432-41. doi: 10.1111/bju.12118

124. Gao J, Wang X, Wang Y, Han F, Cai W, Zhao B, et al. Murine Sertoli Cells Promote the Development of Tolerogenic Dendritic Cells: A Pivotal Role of Galectin-1. Immunology (2016) 148(3):253-65. doi: 10.1111/imm.12598

125. Duan YG, Yu CF, Novak N, Bieber T, Zhu CH, Schuppe HC, et al. Immunodeviation Towards a Th17 Immune Response Associated With Testicular Damage in Azoospermic Men. Int J Androl (2011) 34(6 Pt 2): e536-45. doi: 10.1111/j.1365-2605.2010.01137.x

126. Freemerman AJ, Johnson AR, Sacks GN, Milner JJ, Kirk EL, Troester MA, et al. Metabolic Reprogramming of Macrophages: Glucose Transporter 1 (GLUT1)-Mediated Glucose Metabolism Drives a Proinflammatory Phenotype. J Biol Chem (2014) 289(11):7884-96. doi: 10.1074/ jbc.M113.522037

127. Krawczyk CM, Holowka T, Sun J, Blagih J, Amiel E, DeBerardinis RJ, et al. Toll-Like Receptor-Induced Changes in Glycolytic Metabolism Regulate Dendritic Cell Activation. Blood (2010) 115(23):4742-9. doi: 10.1182/ blood-2009-10-249540

128. Tannahill GM, Curtis AM, Adamik J, Palsson-McDermott EM, McGettrick AF, Goel G, et al. Succinate is an Inflammatory Signal That Induces IL-1beta Through HIF-1alpha. Nature (2013) 496(7444):238-42. doi: 10.1038/ nature 11986

129. Kelly B, O'Neill LA. Metabolic Reprogramming in Macrophages and Dendritic Cells in Innate Immunity. Cell Res (2015) 25(7):771-84. doi: 10.1038/cr.2015.68

130. Gong J, Zeng Q, Yu D, Duan YG. T Lymphocytes and Testicular Immunity: A New Insight Into Immune Regulation in Testes. Int J Mol Sci (2020) 22 (1):57. doi: 10.3390/ijms22010057

131. Tompkins AB, Hutchinson P, de Kretser DM, Hedger MP. Characterization of Lymphocytes in the Adult Rat Testis by Flow Cytometry: Effects of Activin and Transforming Growth Factor Beta on Lymphocyte Subsets In Vitro. Biol Reprod (1998) 58(4):943-51. doi: 10.1095/biolreprod58.4.943 
132. Lopez-Soto A, Gonzalez S, Smyth MJ, Galluzzi L. Control of Metastasis by NK Cells. Cancer Cell (2017) 32(2):135-54. doi: 10.1016/j.ccell.2017.06.009

133. Jacobo P, Guazzone VA, Jarazo-Dietrich S, Theas MS, Lustig L. Differential Changes in CD4+ and CD8+ Effector and Regulatory T Lymphocyte Subsets in the Testis of Rats Undergoing Autoimmune Orchitis. J Reprod Immunol (2009) 81(1):44-54. doi: 10.1016/j.jri.2009.04.005

134. Wheeler K, Tardif S, Rival C, Luu B, Bui E, Del Rio R, et al. Regulatory T Cells Control Tolerogenic Versus Autoimmune Response to Sperm in Vasectomy. Proc Natl Acad Sci USA (2011) 108(18):7511-6. doi: 10.1073/pnas. 1017615108

135. Hedger MP, Wang J, Lan HY, Atkins RC, Wreford NG. Immunoregulatory Activity in Adult Rat Testicular Interstitial Fluid: Relationship With Intratesticular CD8+ Lymphocytes Following Treatment With Ethane Dimethane Sulfonate and Testosterone Implants. Biol Reprod (1998) 58 (4):935-42. doi: 10.1095/biolreprod58.4.935

136. Campese AF, Grazioli P, de Cesaris P, Riccioli A, Bellavia D, Pelullo M, et al. Mouse Sertoli Cells Sustain De Novo Generation of Regulatory T Cells by Triggering the Notch Pathway Through Soluble JAGGED1. Biol Reprod (2014) 90(3):53. doi: 10.1095/biolreprod.113.113803

137. Poznanski SM, Barra NG, Ashkar AA, Schertzer JD. Immunometabolism of T Cells and NK Cells: Metabolic Control of Effector and Regulatory Function. Inflammation Res (2018) 67(10):813-28. doi: 10.1007/s00011018-1174-3

138. Jacobo P. The Role of Regulatory T Cells in Autoimmune Orchitis. Andrologia (2018) 50(11):e13092. doi: 10.1111/and.13092

139. Doedens AL, Phan AT, Stradner MH, Fujimoto JK, Nguyen JV, Yang E, et al. Hypoxia-Inducible Factors Enhance the Effector Responses of CD8(+) T Cells to Persistent Antigen. Nat Immunol (2013) 14(11):1173-82. doi: $10.1038 /$ ni.2714

140. Peng M, Yin N, Chhangawala S, Xu K, Leslie CS, Li MO. Aerobic Glycolysis Promotes T Helper 1 Cell Differentiation Through an Epigenetic Mechanism. Science (2016) 354(6311):481-4. doi: 10.1126/science.aaf6284

141. Kalinski P. Regulation of Immune Responses by Prostaglandin E2. J Immunol (2012) 188(1):21-8. doi: 10.4049/jimmunol.1101029

142. Keating SE, Zaiatz-Bittencourt V, Loftus RM, Keane C, Brennan K, Finlay DK, et al. Metabolic Reprogramming Supports IFN-Gamma Production by CD56bright NK Cells. J Immunol (2016) 196(6):2552-60. doi: 10.4049/ jimmunol.1501783

143. Keppel MP, Saucier N, Mah AY, Vogel TP, Cooper MA. Activation-Specific Metabolic Requirements for NK Cell IFN-Gamma Production. J Immunol (2015) 194(4):1954-62. doi: 10.4049/jimmunol.1402099

144. Eleftheriadis T, Pissas G, Yiannaki E, Markala D, Arampatzis S, Antoniadi G, et al. Inhibition of Indoleamine 2,3-Dioxygenase in Mixed Lymphocyte Reaction Affects Glucose Influx and Enzymes Involved in Aerobic Glycolysis and Glutaminolysis in Alloreactive T-Cells. Hum Immunol (2013) 74 (12):1501-9. doi: 10.1016/j.humimm.2013.08.268

145. Gianchecchi E, Delfino DV, Fierabracci A. Recent Insights Into the Role of the PD-1/PD-L1 Pathway in Immunological Tolerance and Autoimmunity. Autoimmun Rev (2013) 12(11):1091-100. doi: 10.1016/j.autrev.2013.05.003

146. Beldi-Ferchiou A, Lambert M, Dogniaux S, Vely F, Vivier E, Olive D, et al. PD-1 Mediates Functional Exhaustion of Activated NK Cells in Patients With Kaposi Sarcoma. Oncotarget (2016) 7(45):72961-77. doi: 10.18632/ oncotarget. 12150

147. Mayerhofer A, Walenta L, Mayer C, Eubler K, Welter H. Human Testicular Peritubular Cells, Mast Cells and Testicular Inflammation. Andrologia (2018) 50(11):e13055. doi: 10.1111/and.13055

148. Caslin HL, Taruselli MT, Haque T, Pondicherry N, Baldwin EA, Barnstein $\mathrm{BO}$, et al. Inhibiting Glycolysis and ATP Production Attenuates IL-33Mediated Mast Cell Function and Peritonitis. Front Immunol (2018) 9:3026. doi: 10.3389/fimmu.2018.03026

149. Van den Bossche J, Baardman J, Otto Natasja A, van der Velden S, Neele Annette E, van den Berg Susan M, et al. Mitochondrial Dysfunction Prevents Repolarization of Inflammatory Macrophages. Cell Rep (2016) 17(3):684-96. doi: 10.1016/j.celrep.2016.09.008

150. Gerendai I, Banczerowski P, Csernus V. Interleukin 1- $\beta$ Injected Into the Testis Acutely Stimulates and Later Attenuates Testicular Steroidogenesis of the Immature Rat. Endocrine (2005) 28(2):165-70. doi: 10.1385/ ENDO:28:2:165
151. Huleihel M, Lunenfeld E. Involvement of Intratesticular IL-1 System in the Regulation of Sertoli Cell Functions. Mol Cell Endocrinol (2002) 187(12):125-32. doi: 10.1016/s0303-7207(01)00690-6

152. Bisht $S$, Faiq $M$, Tolahunase $M$, Dada R. Oxidative Stress and Male Infertility. Nat Rev Urol (2017) 14(8):470-85. doi: 10.1038/nrurol.2017.69

153. Tremellen K. Oxidative Stress and Male Infertility-a Clinical Perspective. Hum Reprod Update (2008) 14(3):243-58. doi: 10.1093/humupd/dmn004

154. Hotamisligil GS. Foundations of Immunometabolism and Implications for Metabolic Health and Disease. Immunity (2017) 47(3):406-20. doi: 10.1016/ j.immuni.2017.08.009

155. Ochsendorf FR. Infections in the Male Genital Tract and Reactive Oxygen Species. Hum Reprod Update (1999) 5(5):399-420. doi: 10.1093/humupd/ 5.5.399

156. Lysiak JJ. The Role of Tumor Necrosis Factor-Alpha and Interleukin-1 in the Mammalian Testis and Their Involvement in Testicular Torsion and Autoimmune Orchitis. Reprod Biol Endocrinol (2004) 2(1):9. doi: 10.1186/ 1477-7827-2-9

157. Fraczek M, Kurpisz M. Cytokines in the Male Reproductive Tract and Their Role in Infertility Disorders. J Reprod Immunol (2015) 108:98-104. doi: $10.1016 /$ j.jri.2015.02.001

158. Syriou V, Papanikolaou D, Kozyraki A, Goulis DG. Cytokines and Male Infertility. Eur Cytokine Netw (2018) 29(3):73-82. doi: 10.1684/ ecn.2018.0412

159. La Vignera S, Condorelli RA, Vicari E, Tumino D, Morgia G, Favilla V, et al. Markers of Semen Inflammation: Supplementary Semen Analysis? J Reprod Immunol (2013) 100(1):2-10. doi: 10.1016/j.jri.2013.05.001

160. Agarwal A, Rana M, Qiu E, AlBunni H, Bui AD, Henkel R. Role of Oxidative Stress, Infection and Inflammation in Male Infertility. Andrologia (2018) 50 (11):e13126. doi: 10.1111/and.13126

161. Barati E, Nikzad H, Karimian M. Oxidative Stress and Male Infertility: Current Knowledge of Pathophysiology and Role of Antioxidant Therapy in Disease Management. Cell Mol Life Sci (2020) 77(1):93-113. doi: 10.1007/ s00018-019-03253-8

162. Turner TT, Bang HJ, Lysiak JJ. Experimental Testicular Torsion: Reperfusion Blood Flow and Subsequent Testicular Venous Plasma Testosterone Concentrations. Urology (2005) 65(2):390-4. doi: 10.1016/j.urology. 2004.09.033

163. Darbandi M, Darbandi S, Agarwal A, Sengupta P, Durairajanayagam D, Henkel R, et al. Reactive Oxygen Species and Male Reproductive Hormones. Reprod Biol Endocrinol (2018) 16(1):87. doi: 10.1186/s12958018-0406-2

164. Sikka SC. Oxidative Stress and Role of Antioxidants in Normal and Abnormal Sperm Function. Front Biosci (1996) 1:e78-86. doi: 10.2741/a146

165. Martinez P, Proverbio F, Camejo MI. Sperm Lipid Peroxidation and ProInflammatory Cytokines. Asian J Androl (2007) 9(1):102-7. doi: 10.1111/ j.1745-7262.2007.00238.x

166. Lainez NM, Coss D. Obesity, Neuroinflammation, and Reproductive Function. Endocrinology (2019) 160(11):2719-36. doi: 10.1210/en.201900487

167. Ray I, Mahata SK, De RK. Obesity: An Immunometabolic Perspective. Front Endocrinol (Lausanne) (2016) 7:157. doi: 10.3389/fendo.2016.00157

168. Fui MN, Dupuis P, Grossmann M. Lowered Testosterone in Male Obesity: Mechanisms, Morbidity and Management. Asian J Androl (2014) 16(2):22331. doi: $10.4103 / 1008-682 X .122365$

169. Craig JR, Jenkins TG, Carrell DT, Hotaling JM. Obesity, Male Infertility, and the Sperm Epigenome. Fertil Steril (2017) 107(4):848-59. doi: 10.1016/ j.fertnstert.2017.02.115

170. Leisegang K, Henkel R, Agarwal A. Obesity and Metabolic Syndrome Associated With Systemic Inflammation and the Impact on the Male Reproductive System. Am J Reprod Immunol (2019) 82(5):e13178. doi: $10.1111 /$ aji.13178

171. Arafa M, Agarwal A, Al Said S, Majzoub A, Sharma R, Bjugstad KB, et al. Semen Quality and Infertility Status can be Identified Through Measures of Oxidation-Reduction Potential. Andrologia (2018) 50(2):e12881. doi: $10.1111 /$ and.12881

172. Dutta S, Majzoub A, Agarwal A. Oxidative Stress and Sperm Function: A Systematic Review on Evaluation and Management. Arab J Urol (2019) 17 (2):87-97. doi: 10.1080/2090598X.2019.1599624 
173. Alves MG, Martins AD, Cavaco JE, Socorro S, Oliveira PF. Diabetes, InsulinMediated Glucose Metabolism and Sertoli/blood-Testis Barrier Function. Tissue Barriers (2013) 1(2):e23992. doi: 10.4161/tisb.23992

174. Street EJ, Justice ED, Kopa Z, Portman MD, Ross JD, Skerlev M, et al. The 2016 European Guideline on the Management of Epididymo-Orchitis. Int $J$ STD AIDS (2017) 28(8):744-9. doi: 10.1177/0956462417699356

175. Guzik TJ, Cosentino F. Epigenetics and Immunometabolism in Diabetes and Aging. Antioxid Redox Signal (2018) 29(3):257-74. doi: 10.1089/ ars.2017.7299

176. Majzoub A, Agarwal A. Systematic Review of Antioxidant Types and Doses in Male Infertility: Benefits on Semen Parameters, Advanced Sperm Function, Assisted Reproduction and Live-Birth Rate. Arab J Urol (2018) 16(1):113-24. doi: 10.1016/j.aju.2017.11.013

177. Agarwal A, Parekh N, Panner Selvam MK, Henkel R, Shah R, Homa ST, et al. Male Oxidative Stress Infertility (MOSI): Proposed Terminology and Clinical Practice Guidelines for Management of Idiopathic Male Infertility. World J Mens Health (2019) 37(3):296-312. doi: 10.5534/wjmh.190055

178. Francomano D, Ilacqua A, Bruzziches R, Lenzi A, Aversa A. Effects of 5-Year Treatment With Testosterone Undecanoate on Lower Urinary Tract Symptoms in Obese Men With Hypogonadism and Metabolic Syndrome. Urology (2014) 83(1):167-73. doi: 10.1016/j.urology.2013.08.019

179. Diaz A, Romero M, Vazquez T, Lechner S, Blomberg BB, Frasca D. Metformin Improves In Vivo and In Vitro B Cell Function in Individuals With Obesity and Type-2 Diabetes. Vaccine (2017) 35(20):2694-700. doi: 10.1016/j.vaccine.2017.03.078

180. Zarrouk M, Finlay DK, Foretz M, Viollet B, Cantrell DA. Adenosine-MonoPhosphate-Activated Protein Kinase-Independent Effects of Metformin in T Cells. PloS One (2014) 9(9):e106710. doi: 10.1371/journal.pone.0106710

181. Palsson-McDermott EM, O’Neill LAJ. Targeting Immunometabolism as an Anti-Inflammatory Strategy. Cell Res (2020) 30(4):300-14. doi: 10.1038/ s41422-020-0291-z

182. Mir J, Ashraf M. Does Weight Loss Improve Fertility With Respect to Semen Parameters- Results From a Large Cohort Study. Int J Infertil Fetal Med (2017) 8:12-7. doi: 10.5005/jp-journals-10016-1141

183. Salehi B, Martorell M, Arbiser JL, Sureda A, Martins N, Maurya PK, et al. Antioxidants: Positive or Negative Actors? Biomolecules (2018) 8(4):124. doi: 10.3390/biom 8040124

184. Schisterman EF, Sjaarda LA, Clemons T, Carrell DT, Perkins NJ, Johnstone E, et al. Effect of Folic Acid and Zinc Supplementation in Men on Semen Quality and Live Birth Among Couples Undergoing Infertility Treatment: A Randomized Clinical Trial. JAMA (2020) 323(1):35-48. doi: 10.1001/ jama.2019.18714

185. Steiner AZ, Hansen KR, Barnhart KT, Cedars MI, Legro RS, Diamond MP, et al. The Effect of Antioxidants on Male Factor Infertility: The Males, Antioxidants, and Infertility (MOXI) Randomized Clinical Trial. Fertil Steril (2020) 113552-560(3):e553. doi: 10.1016/j.fertnstert.2019.11.008

186. Smits RM, Mackenzie-Proctor R, Yazdani A, Stankiewicz MT, Jordan V, Showell MG. Antioxidants for Male Subfertility. Cochrane Database Syst Rev (2019) 3:CD007411. doi: 10.1002/14651858.CD007411.pub4

187. Alves MG, Martins AD, Vaz CV, Correia S, Moreira PI, Oliveira PF, et al. Metformin and Male Reproduction: Effects on Sertoli Cell Metabolism. Br J Pharmacol (2014) 171(4):1033-42. doi: 10.1111/bph.12522

188. Tavares RS, Escada-Rebelo S, Silva AF, Sousa MI, Ramalho-Santos J, Amaral S. Antidiabetic Therapies and Male Reproductive Function: Where do We Stand? Reproduction (2018) 155(1):R13-37. doi: 10.1530/REP-17-0390

189. Maresch CC, Stute DC, Alves MG, Oliveira PF, de Kretser DM, Linn T. Diabetes-Induced Hyperglycemia Impairs Male Reproductive Function: A Systematic Review. Hum Reprod Update (2018) 24(1):86-105. doi: 10.1093/ humupd/dmx033

190. Su Y, Lu J, Chen X, Liang C, Luo P, Qin C, et al. Rapamycin Alleviates Hormone Imbalance-Induced Chronic Nonbacterial Inflammation in Rat Prostate Through Activating Autophagy via the mTOR/ULK1/ATG13
Signaling Pathway. Inflammation (2018) 41(4):1384-95. doi: 10.1007/ s10753-018-0786-7

191. Zhang L, Liu Y, Chen XG, Zhang Y, Chen J, Hao ZY, et al. MicroRNA Expression Profile in Chronic Nonbacterial Prostatitis Revealed by NextGeneration Small RNA Sequencing. Asian J Androl (2019) 21(4):351-9. doi: 10.4103/aja.aja_97_18

192. Aslani F, Schuppe HC, Guazzone VA, Bhushan S, Wahle E, Lochnit G, et al. Targeting High Mobility Group Box Protein 1 Ameliorates Testicular Inflammation in Experimental Autoimmune Orchitis. Hum Reprod (2015) 30(2):417-31. doi: 10.1093/humrep/deu320

193. Nicolas N, Muir JA, Hayward S, Chen JL, Stanton PG, Gregorevic P, et al. Induction of Experimental Autoimmune Orchitis in Mice: Responses to Elevated Circulating Levels of the Activin-Binding Protein, Follistatin. Reproduction (2017) 154(3):293-305. doi: 10.1530/REP-17-0010

194. Winter AG, Zhao F, Lee RK. Androgen Deficiency and Metabolic Syndrome in Men. Transl Androl Urol (2014) 3(1):50-8. doi: 10.3978/j.issn.22234683.2014.01.04

195. Vabret N, Britton GJ, Gruber C, Hegde S, Kim J, Kuksin M, et al. Immunology of COVID-19: Current State of the Science. Immunity (2020) 52(6):910-41. doi: 10.1016/j.immuni.2020.05.002

196. Yang M, Chen S, Huang B, Zhong JM, Su H, Chen YJ, et al. Pathological Findings in the Testes of COVID-19 Patients: Clinical Implications. Eur Urol Focus (2020) 6(5):1124-9. doi: 10.1016/j.euf.2020.05.009

197. Sliwa L, Macura B, Majewska-Szczepanik M, Szczepanik M. Lack of TCRalphabeta+ CD8+ and TCRgammadelta+ Lymphocytes Ameliorates LPS Induced Orchitis in Mice-Preliminary Histological Observations. Folia Biol (Krakow) (2014) 62(1):67-71. doi: 10.3409/fb62_1.67

198. Hedger MP, Meinhardt A. Local Regulation of T Cell Numbers and Lymphocyte-Inhibiting Activity in the Interstitial Tissue of the Adult Rat Testis. J Reprod Immunol (2000) 48(2):69-80. doi: 10.1016/s0165-0378(00) 00071-1

199. Firth JD, Ebert BL, Ratcliffe PJ. Hypoxic Regulation of Lactate Dehydrogenase A. Interaction Between Hypoxia-Inducible Factor 1 and cAMP Response Elements. J Biol Chem (1995) 270(36):21021-7. doi: $10.1074 /$ jbc.270.36.21021

200. Crisostomo L, Alves MG, Gorga A, Sousa M, Riera MF, Galardo MN, et al. Molecular Mechanisms and Signaling Pathways Involved in the Nutritional Support of Spermatogenesis by Sertoli Cells. Methods Mol Biol (2018) 1748:129-55. doi: 10.1007/978-1-4939-7698-0_11

201. Cardoso AM, Alves MG, Mathur PP, Oliveira PF, Cavaco JE, Rato L. Obesogens and Male Fertility. Obes Rev (2017) 18(1):109-25. doi: 10.1111/obr.12469

202. Grossmann M. Hypogonadism and Male Obesity: Focus on Unresolved Questions. Clin Endocrinol (Oxf) (2018) 89(1):11-21. doi: 10.1111/cen.13723

203. Pereira SC, Crisostomo L, Sousa M, Oliveira PF, Alves MG. Metabolic Diseases Affect Male Reproduction and Induce Signatures in Gametes That may Compromise the Offspring Health. Environ Epigenet (2020) 6(1): dvaa019. doi: 10.1093/eep/dvaa019

204. Luo D, Zhang M, Su X, Liu L, Zhou X, Zhang X, et al. High Fat Diet Impairs Spermatogenesis by Regulating Glucose and Lipid Metabolism in Sertoli Cells. Life Sci (2020) 257:118028. doi: 10.1016/j.lfs.2020.118028

Conflict of Interest: The authors declare that the research was conducted in the absence of any commercial or financial relationships that could be construed as a potential conflict of interest.

Copyright $\odot 2021$ Ye, Huang, Liu, Cai, Hong, Xiao, Thiele, Zeng, Song and Diao. This is an open-access article distributed under the terms of the Creative Commons Attribution License (CC BY). The use, distribution or reproduction in other forums is permitted, provided the original author $(s)$ and the copyright owner(s) are credited and that the original publication in this journal is cited, in accordance with accepted academic practice. No use, distribution or reproduction is permitted which does not comply with these terms. 